\title{
A Region-Dependent Seasonal Forecasting Framework for Tropical Cyclone Genesis Frequency in the Western North Pacific
}

\author{
CHAO WANG \\ Key Laboratory of Meteorological Disaster of Ministry of Education, Joint International Research Laboratory of Climate and \\ Environment Change, Collaborative Innovation Center on Forecast and Evaluation of Meteorological Disasters, Nanjing University \\ of Information Science and Technology, Nanjing, China, and Department of Atmospheric Sciences and International Pacific Research \\ Center, University of Hawai' $i$ at Mānoa, Honolulu, Hawaii

\section{BIN WANG} \\ Department of Atmospheric Sciences and International Pacific Research Center, University of Hawai'i at Mānoa, \\ Honolulu, Hawaii, and Earth System Modeling Center, Nanjing University \\ of Information Science and Technology, Nanjing, China

\section{LIGUANG WU} \\ Key Laboratory of Meteorological Disaster of Ministry of Education, Joint International Research Laboratory of Climate and Environment \\ Change, Collaborative Innovation Center on Forecast and Evaluation of Meteorological Disasters, Nanjing University of Information \\ Science and Technology, Nanjing, China
}

(Manuscript received 3 January 2019, in final form 21 August 2019)

\begin{abstract}
It has been a common practice to predict total tropical cyclone (TC) genesis frequency over the entire western North Pacific (WNP). Here we show that TC genesis (TCG) exhibits distinct regional variability and sources of predictability. Therefore, we divide the WNP into four quadrants with $140^{\circ} \mathrm{E}$ and $17^{\circ} \mathrm{N}$ being dividing lines plus the South China Sea (SCS) to predict five subregional TCG frequencies as well as the entire WNP TCG frequency. Besides the well-known ENSO-induced seesaw relationship between the TCGs in the southeast and northwest quadrants, we found that 1) an enhanced TCG in the northeast WNP is associated with a pronounced anomalous cyclonic circulation, which is maintained through its interaction with the underlying sea surface temperature (SST) anomalies; 2) an active TCG in the southwest WNP is accompanied by a zonally elongated positive vorticity anomaly and SST warming over the equatorial eastern Pacific; and 3 ) the SCS TCG is influenced by the upper-level South Asia high through modulating large-scale environmental parameters. Physically meaningful predictors are identified and a set of empirical prediction models for TCG frequency is established for each subregion. Both the cross-validated reforecast for 1965-2000 and independent forecast for 2001-16 show significant temporal correlation skills. Moreover, the sum of the predicted TCG frequency in five subregions yields a basinwide TCG frequency prediction with a temporal correlation skill of 0.76 for the independent forecast period of 2001-16. The results indicate its potential utility to improve the TC forecasting in the WNP.
\end{abstract}

\section{Introduction}

The western North Pacific (WNP) hosts about onethird of global named tropical cyclones (TCs) per year (Gray 1968; Chan 2005) and experiences large year to year fluctuation in the total tropical storm days (Wang et al. 2010). Billions of people living in Pacific islands

Corresponding author: Chao Wang, wangchao.typhoon@gmail. com and Asian coastal regions are frequently subject to TCinduced disasters (Zhang et al. 2009; Peduzzi et al. 2012). Skillful seasonal prediction for TC activity would immensely benefit disaster mitigation (King et al. 2010). Therefore, achieving skillful seasonal forecasting products has been at the heart of the TC research community since the 1970s (Nicholls 1979; Gray 1984; Chan et al. 1998; Camargo et al. 2007a, 2010; Zhan et al. 2012).

For the WNP, seasonal forecasting of TC activity was first attempted by the National Climate Center of the 


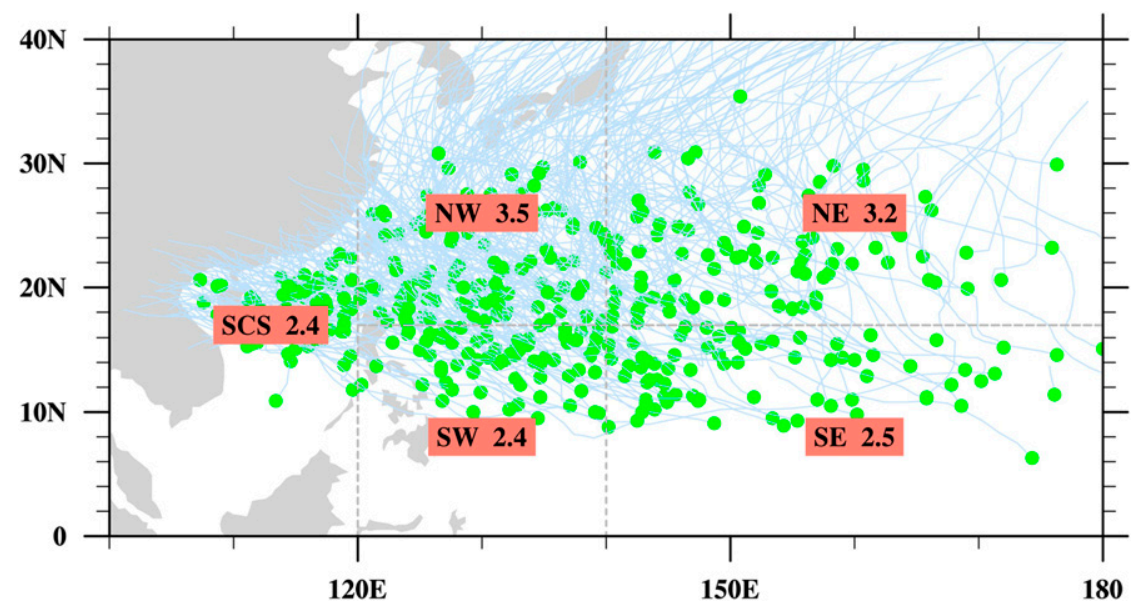

FIG. 1. Climatological TC geneses and tracks over the WNP. TC genesis locations (green dots) and tracks (light blue lines) during July-September over 1965-2016. The gray dashed lines indicate the boundaries of five subregions: South China Sea (SCS), southwest WNP (SW), northwest WNP (NW), southeast WNP (SE), and northeast WNP (NE). Numbers represent the annual mean TC genesis frequency in individual subregions.

China Meteorological Administration in the early 1990s (Zhan et al. 2012). Then, Chan et al. (1998) first issued seasonal forecasting products for the WNP by taking large-scale atmospheric and oceanic conditions into their statistical prediction model. Currently, various strategies including statistical methods, coupled dynamic models, and the so-called hybrid statistical-dynamical approach have been used to make seasonal outlooks for
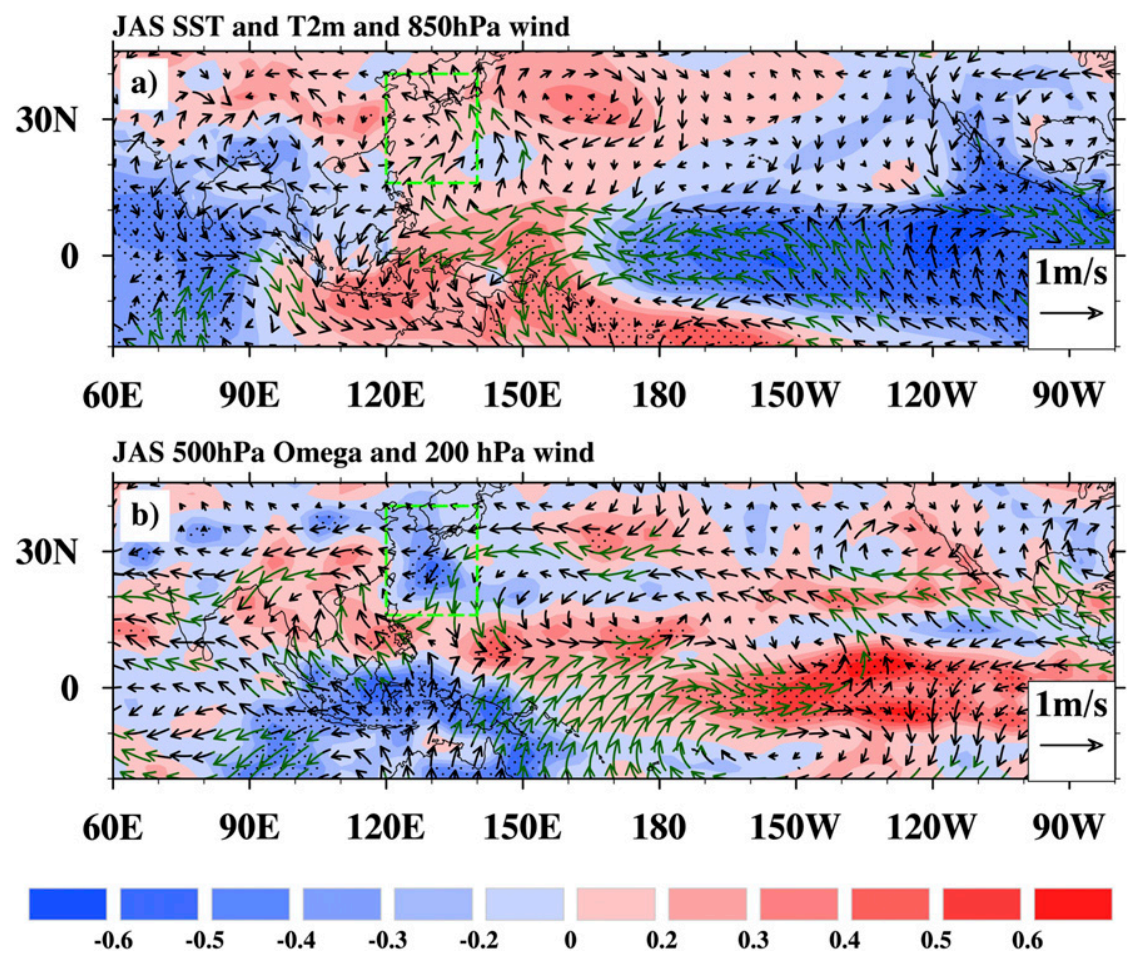

FIG. 2. Large-scale circulation pattern and boundary condition anomalies favoring TCG in the northwest WNP. Simultaneous correlation map between TCG frequency in the northwest WNP and (a) SST (over ocean) and T2m (over land) (shadings) and 850-hPa wind (vectors) and (b) 500-hPa omega (shadings) and 200-hPa wind (vectors) in July-September during 1965-2000. The green vectors and dotted areas denote regions with correlation coefficients significant at the $95 \%$ confidence level. The green boxes indicate boundaries of the northwest WNP. 


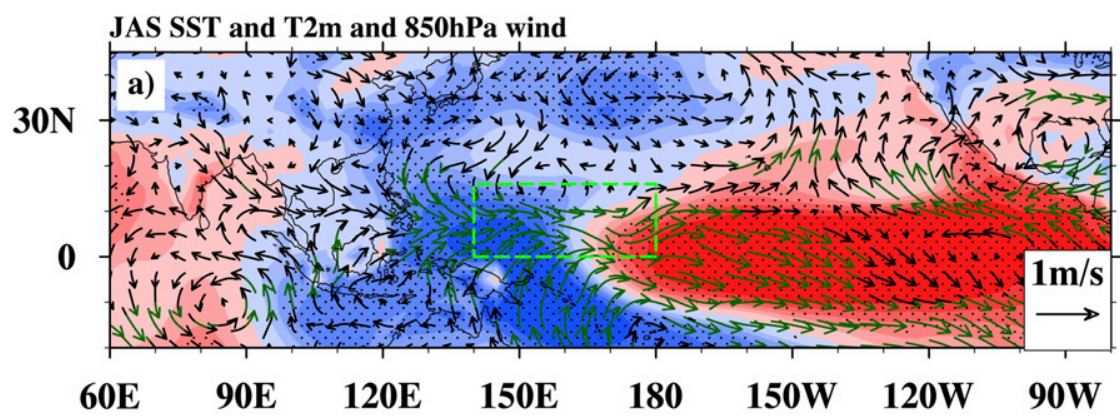

JAS 500hPa Omega and $200 \mathrm{hPa}$ wind

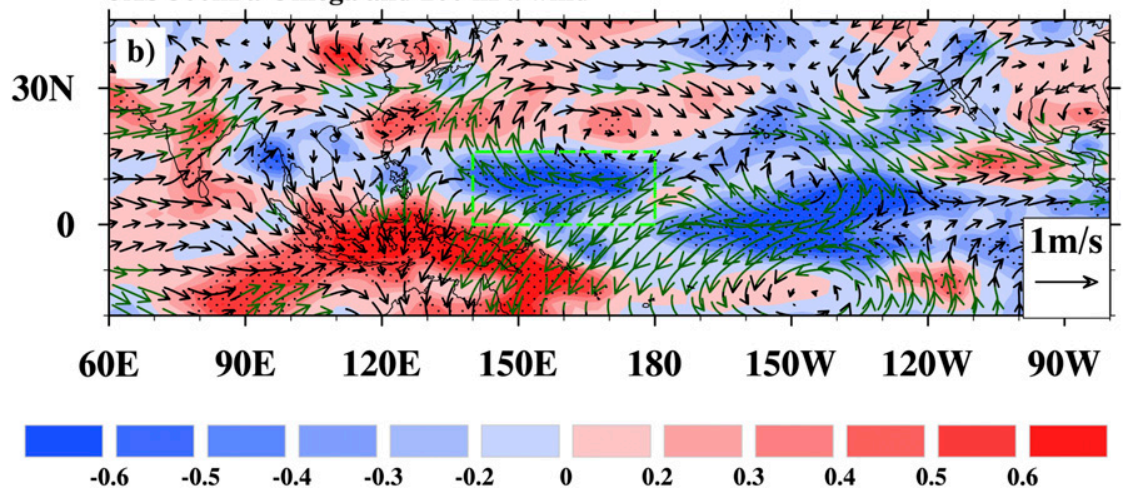

FIG. 3. As in Fig. 2, but for the southeast WNP.

the WNP TC activity (Chan et al. 1998, 2001; Camargo et al. 2007a, 2010; Chen and Lin 2013; Zhan and Wang 2016; Zhang et al. 2016b). While the coupled dynamic models gradually have shown valuable prediction skill in recent decades (Chen and Lin 2013; Vecchi et al. 2014; Camp et al. 2015; Manganello et al. 2016), the statistical approach is still the principal way to issue TC seasonal forecasts over the WNP (Chan et al. 1998, 2001; Camargo
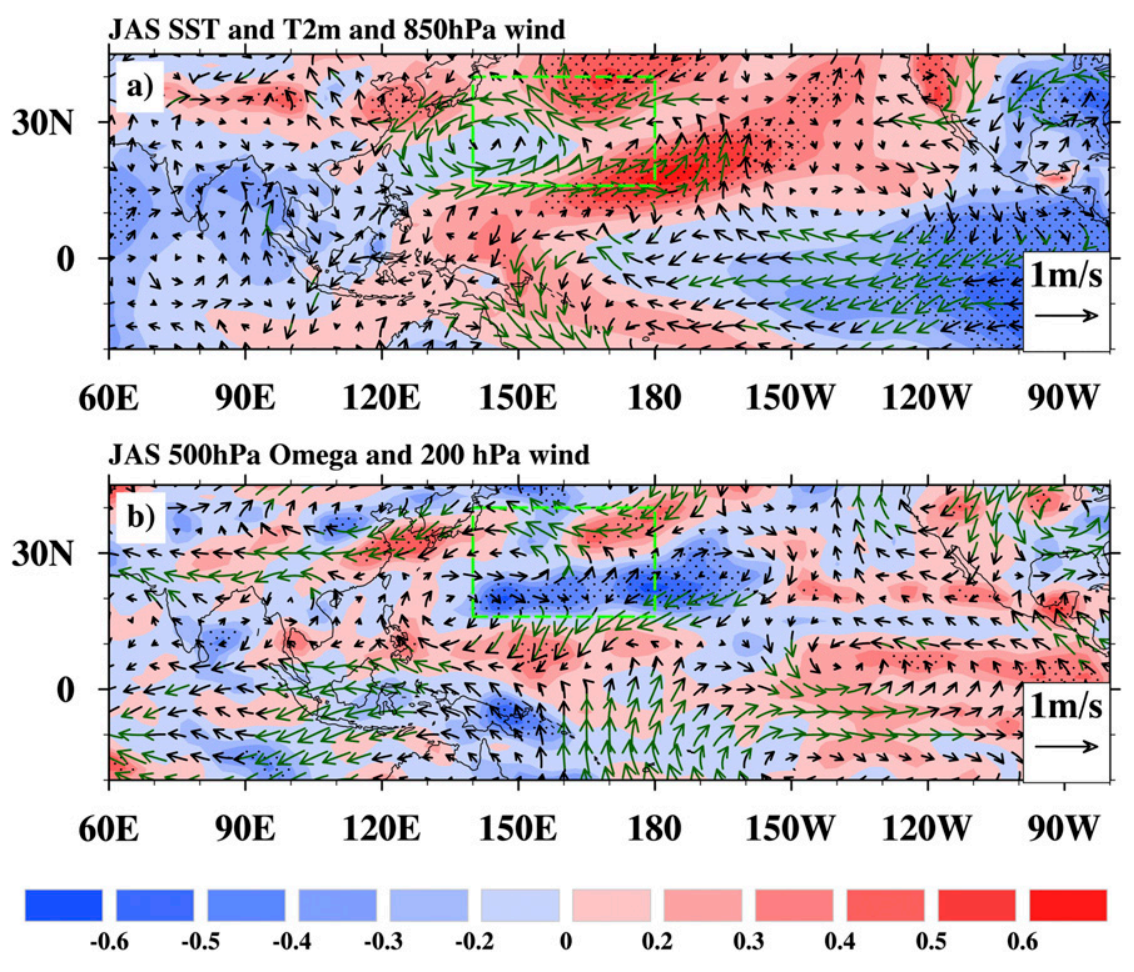

FIG. 4. As in Fig. 2, but for the northeast WNP. 

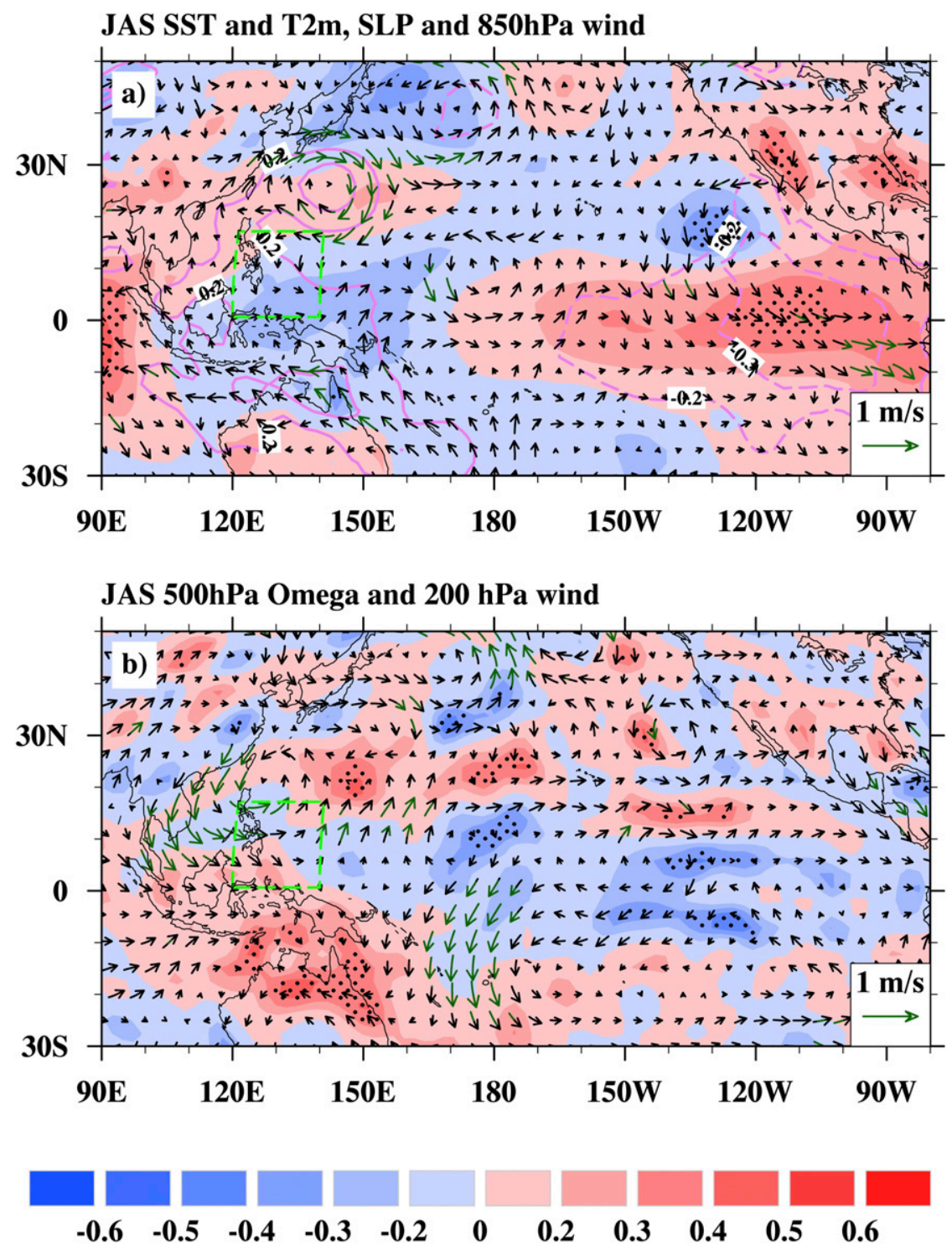

FIG. 5. Large-scale circulation pattern and boundary condition anomalies favoring TCG in the southwest WNP. Simultaneous correlation map between TCG frequency in the southwest WNP and (a) SST (over ocean) and T2m (over land) (shadings), SLP (contours), and 850-hPa wind (vectors) and (b) 500-hPa omega (shadings) and $200-\mathrm{hPa}$ wind (vectors) in JulySeptember during 1965-2000. The green vectors and dotted areas denote regions with correlation coefficients significant at the $95 \%$ confidence level. The green boxes indicate boundaries of the southwest WNP.

et al. 2007a, 2010; Fan and Wang 2009; Lu et al. 2010; Zhan et al. 2012; Zhan and Wang 2016; Kim et al. 2017; Zhang et al. 2018; Wang and Wang 2019).

Various factors have been used to predict the TC genesis (TCG) frequency over the WNP, including El Niño-Southern Oscillation (ENSO) (Chan et al. 1998, 2001; Wang and Chan 2002; Zhao 2016; Zhao and Wang 2016; Wang et al. 2019a,b; Zhao and Wang 2019), the North Pacific Oscillation (H. Wang et al. 2007; Chen et al. 2015; Zhang et al. 2018), the Antarctic Oscillation (Ho et al. 2005; Wang and Fan 2007), and the Hadley circulation (Zhou and Cui 2008). More recently, the Pacific meridional mode (PMM; Zhang et al. 2016a), SST variations in the Indian Ocean (Du et al. 2011; Zhan et al. 2011a; Tao et al. 2012) and North Atlantic (Huo et al. 2015), and the SST gradient between the southwestern Pacific and the western Pacific warm pool (Zhou and Cui 2011; Zhan et al. 2013) have been suggested to 
JAS 200 hPa wind and 500 hPa Omega

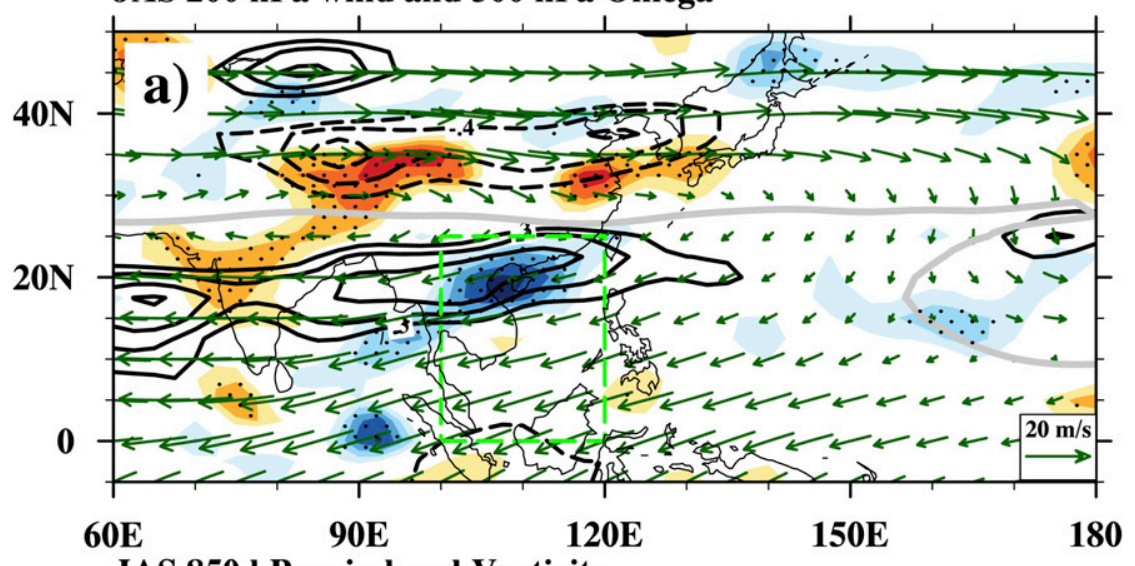

JAS 850 hPa wind and Vorticity
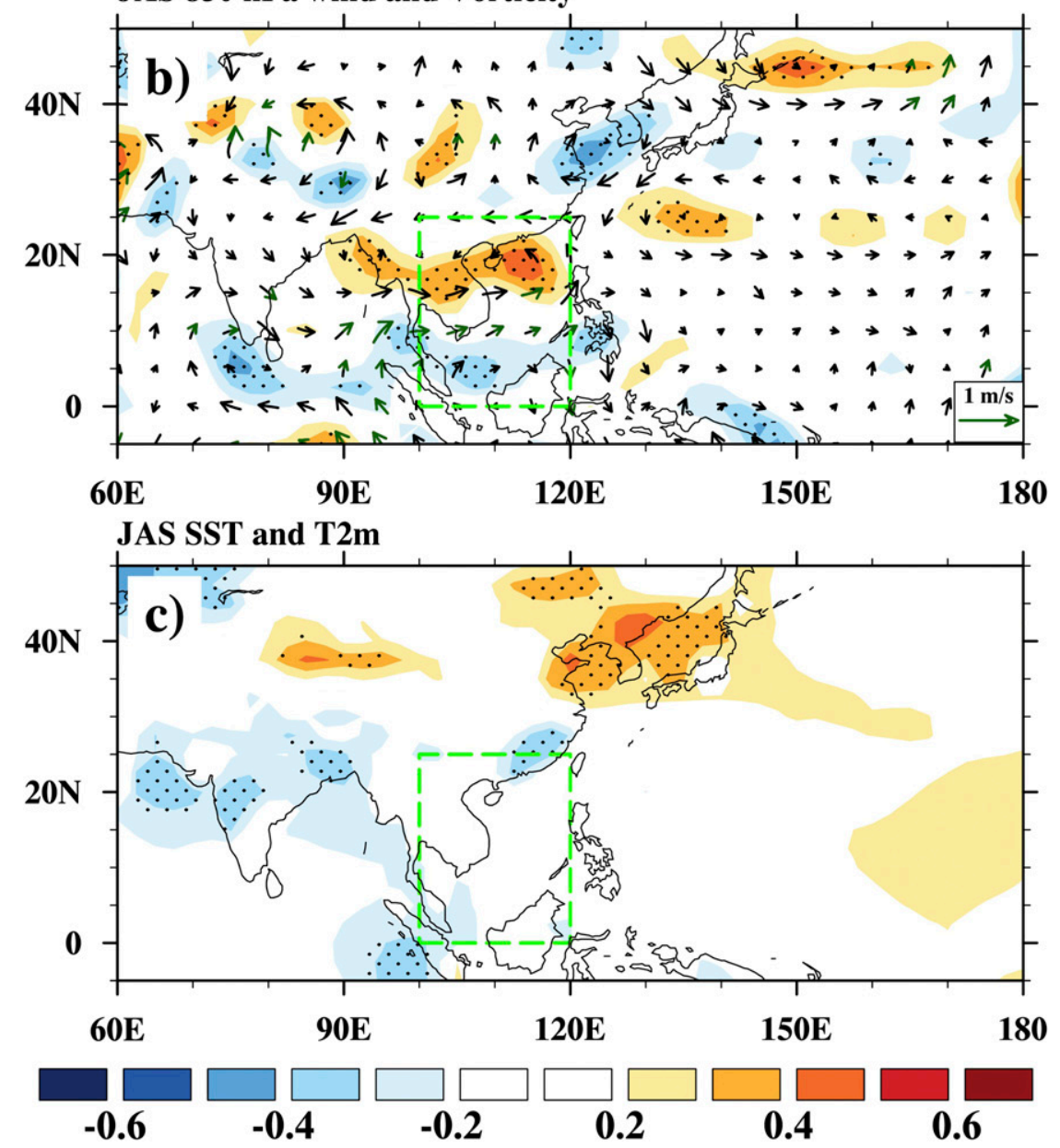

FIG. 6. Large-scale circulation patterns and boundary conditions anomalies favoring TCG in the South China Sea. Simultaneous correlation map between TCG frequency in the South China Sea and (a) 200-hPa zonal wind (black contours) and 500-hPa omega (shadings), (b) 850$\mathrm{hPa}$ winds (vectors) and vorticity (shadings), and (c) SST in July-September during 1965-2000. The green vectors in (b) and dotted areas denote regions with correlation coefficients significant at the $95 \%$ confidence level. The vectors in (a) display the climatological 200-hPa wind, indicating the mean circulation associated with the South Asian high. The gray line in (a) shows the zero contour of the climatological 200-hPa zonal wind, which denotes the ridge of the South Asian high. The green boxes indicate the boundaries of the South China Sea. 

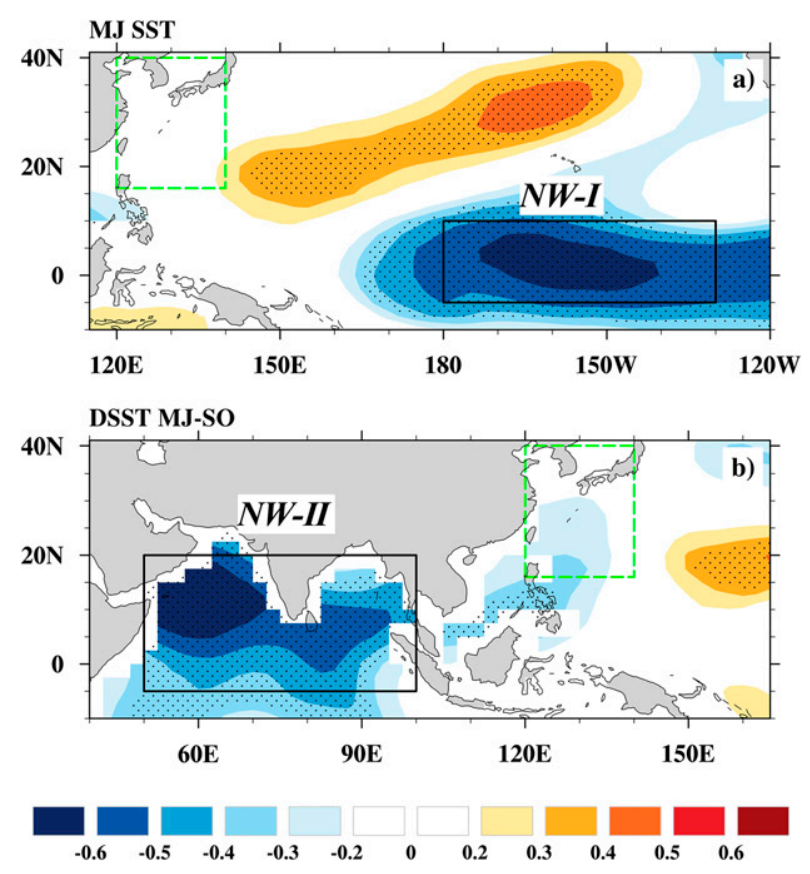

FIG. 7. Predictors for TCG frequency in the northwest WNP. Correlation map between TCG frequency in the northwest WNP and (a) May-June mean SST and (b) SST tendency from September-October to May-June during 1965-2000. Dotted areas denote regions with correlation coefficients significant at the $95 \%$ confidence level. The black boxes represent the locations of predictors, and green boxes indicate boundaries of the northwest WNP.

be potential predictors for TCG frequency over the WNP. Recently, Wang and Wang (2019) found that the two leading modes of the WNP subtropical high integrate the influences of the transbasin SST variations, including the north Indian Ocean (Zhan et al. 2011b; Du et al. 2011), North Pacific (Lander 1994; Wang and Chan 2002), and North Atlantic (Huo et al. 2015), on the WNP TC activity. Therefore, the WNP subtropical high can establish a unified framework for the seasonal forecasting of WNP TC activity (Wang and Wang 2019).

All of the aforementioned statistical prediction schemes usually take the basinwide TCG frequency over the whole WNP as the targeted predictand. However, TCG over the WNP experiences distinct regional features (Wang and Chan 2002; Kim et al. 2010) and the predictability sources of TCG in individual WNP subregions may differ from each other (Kim et al. 2009; Lu et al. 2010). Variations of the TCG frequency in individual subregions are usually not in phase and are even antivaried in some specific subregions (figure not shown). In fact, even to the same climate factor, TCGs in different subregions respond differently due to the diverse responses in local large-scale conditions over the vast WNP (Wang and Chan 2002). The nonunified variation in subregions might make it difficult to predict the TCG frequency over the entire WNP as a whole. In addition, TC disasters vary regionally (Pielke et al. 2008; Zhang et al. 2009; Peduzzi et al. 2012) and so the basinwide TC activity metrics usually act as a poor indicator to those in subregions (Vecchi et al. 2014; Kossin 2017). The utility of these statistical forecasts would therefore be enhanced if seasonal TCG on scales finer than basinwide could be skillfully predicted (Vecchi et al. 2014). Therefore, the primary objectives of this study are to investigate the predictability sources of regional TCG frequency, and further to establish empirical models to predict the seasonal TCG frequency in individual subregions over the WNP.

In the next section, we describe the data and methods to establish and evaluate the prediction models. Section 3 explores the physical interpretation of TCG in individual subregions from the perspective of large-scale conditions. Section 4 presents the identified predictors for each of five subregions. The region-dependent seasonal forecasts and its predicting skill are shown in section 5 and a summary of the results and discussions are presented in section 6 .

\section{Data and method}

\section{a. Data and definition of subregions}

TCG frequency is derived from the Joint Typhoon Warming Center (JTWC), which provides 6-hourly records of positions (latitudes and longitudes) and maximum sustained wind speeds of TCs. TCs in this study are defined as tropical storms whose maximum wind speeds reach or exceed $17.2 \mathrm{~m} \mathrm{~s}^{-1}$. Monthly atmospheric data from the National Centers for Environmental Prediction (NCEP)-National Center for Atmospheric Research (NCAR) reanalysis (Kalnay et al. 1996) and SST from the Extended Reconstructed SST (ERSST) version 4 (Huang et al. 2015) are used to interpret the impacts of large-scale conditions on TCG and identify the potential predictors.

The analysis period is from 1965 to 2016, and we focus on the peak season (July-September; Wang and Chan 2002; Wang and Wu 2012) of TCG over the WNP $\left(0^{\circ}-40^{\circ} \mathrm{N}, 100^{\circ} \mathrm{E}-180^{\circ}\right)$. Note that 1965 is taken as the starting year because satellite monitoring became routine around this year and TCs would be unlikely to be missed (Wang and Chan 2002; Chan 2006). The WNP is divided into five subregions (Fig. 1), the South China Sea $\left(0^{\circ}-25^{\circ} \mathrm{N}, 100^{\circ}-120^{\circ} \mathrm{E}\right)$, southwest WNP $\left(0^{\circ}-17^{\circ} \mathrm{N}, \quad 120^{\circ}-140^{\circ} \mathrm{E}\right)$, northwest WNP $\left(17^{\circ}-40^{\circ} \mathrm{N}\right.$, $\left.120^{\circ}-140^{\circ} \mathrm{E}\right)$, southeast WNP $\left(0^{\circ}-17^{\circ} \mathrm{N}, 140^{\circ} \mathrm{E}-180^{\circ}\right)$, and 

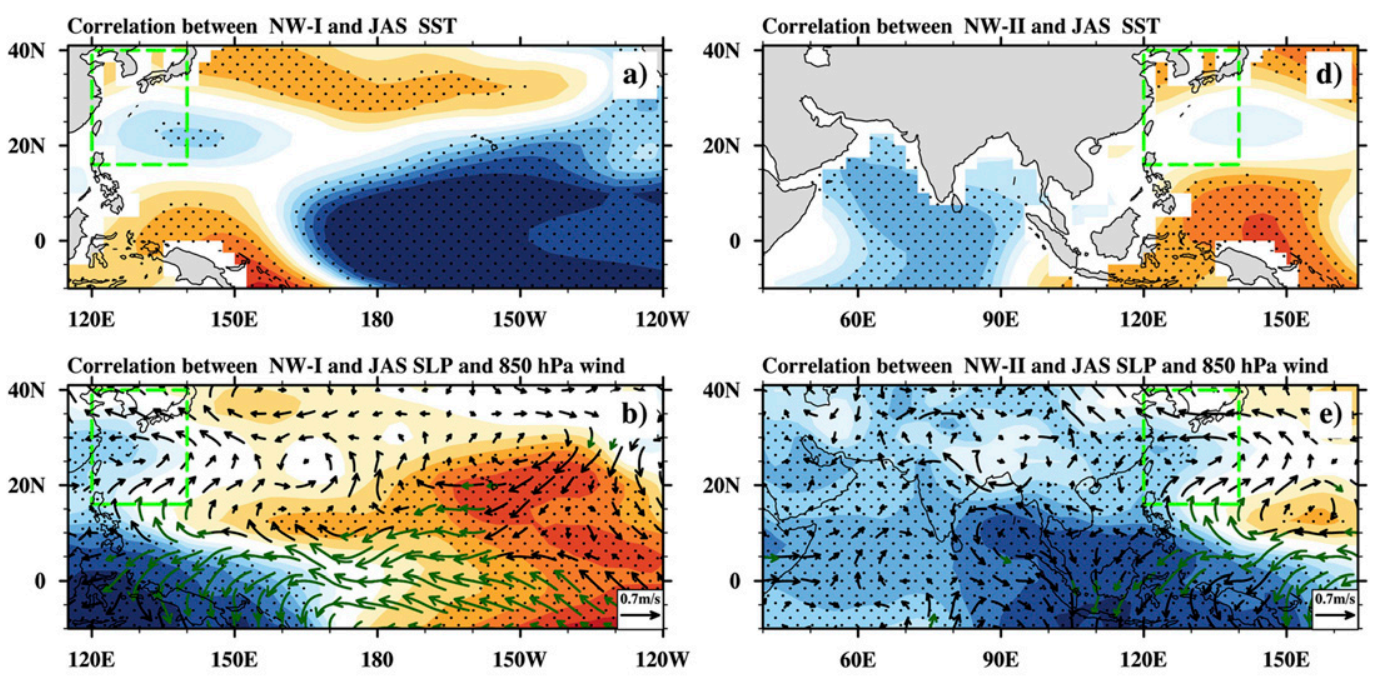

Correlation between NW-I and JAS $500 \mathrm{hPa}$ Omega
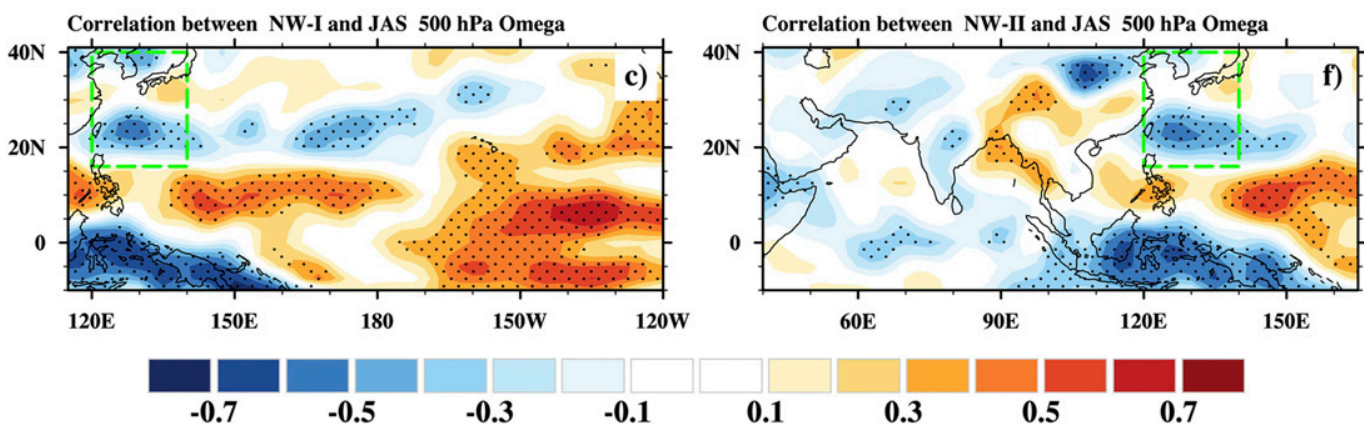

FIG. 8. The lead-lag correlation between predictors for TCG in the northwest WNP and July-September mean large-scale conditions. Correlation maps between NW-I and July-September mean (a) SST, (b) SLP (shadings) and 850-hPa wind (vectors), and (c) 500-hPa omega during 1979-2000. (d)-(f) As in (a)-(c), but for predictor NW-II. The green vectors and dotted areas denote regions with correlation coefficients significant at the $95 \%$ confidence level. The green boxes indicate boundaries of the northwest WNP.

northwest WNP $\left(17^{\circ}-40^{\circ} \mathrm{N}, 140^{\circ} \mathrm{E}-180^{\circ}\right)$, following Wang and Chan (2002).

\section{b. Methods to build and validate empirical models}

Following Wang et al. (2015b), correlation maps between the predictands (i.e., TCG frequency in five subregions during July-September) and anomalous large-scale conditions [SST, 2-m temperature (T2M), sea level pressure (SLP), and $850-\mathrm{hPa}$ wind] prior to July are used to identify the potential predictors. Monthly/bimonthly mean anomalies and tendency in large-scale conditions are taken as the potential predictive signals. Two types of predictors were used: 1 ) the persistent signals (represented by the seasonal mean) that indicate the slow variation of the lower boundary anomalies that will "persist" into the ensuing season, and 2) the tendency signals (represented by the difference in 2-month mean) that signify the tendency of following evolution. The potential predictive signals are identified as a potential predictor if there is a large area of grid points where the correlation coefficient is significant at the $95 \%$ confidence level (Lee et al. 2013; Yim et al. 2014; Wang et al. 2015b). After the above-mentioned two steps, several identified physical meaningful predictors are considered as candidates. Then, stepwise regression, which can ascertain the relative independency of predictors and the best combination of the predictors, is used to build the empirical model for each subregion. A $95 \%$ confidence level for Fisher's $F$ test is used as the criterion to select predictors (Yim et al. 2014; Wang et al. 2015b). The lead-lag correlations between predictors and July-September mean large-scale circulation and environmental parameters are used to understand the causeand-effect relationships between the predictors and predictand. Two validation methods, including crossvalidated reforecast and independent forecast, are adopted to evaluate the prediction skills of empirical models (Wang et al. 2013; Yim et al. 2014). The crossvalidated reforecast is obtained by first building the empirical model with samples excluding three years each 

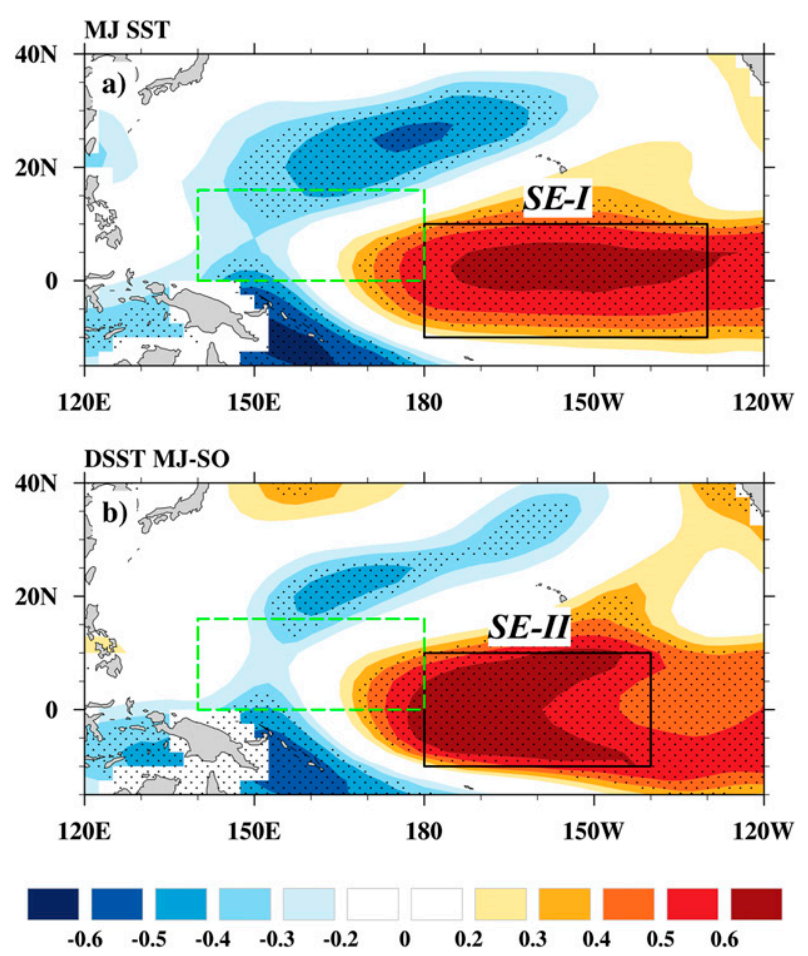

FIG. 9. Predictor for TCG frequency in the southeast WNP. Correlation map between TCG frequency over the southeast WNP and (a) May-June mean SST and (b) SST tendency from SeptemberOctober to May-June during 1965-2000. Dotted areas denote regions with correlation coefficients significant at the $95 \%$ confidence level. The black boxes represent the location of predictors, and green boxes indicate boundaries of the southeast WNP.

time, and then using the derived empirical model to predict the TCG frequency for the three withheld years (Michaelsen 1987). These processes are then repeated for all other years to obtain the cross-validated reforecast for 1965-2000. The independent forecast is then conducted for the remaining 16-yr period (2001-16). Both the predictor selection and the empirical model building are based on the samples during 1965-2000. The temporal correlation coefficient (TCC) and mean square skill score (MSSS) are used to measure the deterministic seasonal forecast skill (Murphy 1988). The MSSS compares the mean square error (MSE) of the forecast to the MSE of climatology and thus reflects the forecast skill relative to the "forecasts" of climatology. Statistical significance of correlation is assessed using the two-tailed Student's $t$ test (Wilks 2006).

\section{Physical interpretation of regional TCG frequency over the WNP}

Large-scale atmospheric and oceanic conditions play a crucial role in TCG over the WNP (Gray 1968; Emanuel and Nolan 2004; Murakami and Wang 2010). In this section, we examine the anomalous large-scale circulation patterns and the corresponding boundary conditions concurring with the anomalous TCG frequency in individual subregions, which can help us gain insight into the physical linkage between the predictor and TCG frequency.

\section{a. The northwest and southeast WNP}

It has long been known that TCG in the northwest and southeast WNP is tightly linked to the ENSO phenomenon (Lander 1994; Wang and Chan 2002; Camargo et al. 2007b; Zhao et al. 2010; Wang and Wu 2016, 2018a). Generally, the favorable large-scale circulation patterns for TCG in the northwest and southeast WNP are consistent with previous studies (Figs. 2 and 3).

An active TCG in the northwest WNP is usually concurrent with a La Niña-like pattern in SST anomalies (Fig. 2a). The anomalous convective heating related to SST cooling over the equatorial central Pacific and SST warming over the Marine Continent can extend the subtropical high eastward through stimulating Rossby and Kelvin wave responses, respectively (Wang et al. 2013). The subtropical high ridge extends to the Philippines, generating cyclonic shear vorticity to its western flank (Fig. 2a) and favoring TCG in the northwest WNP. At the upper troposphere, the anomalous southeasterly in south China and northwesterly to its east generate strong upper-level divergence in the northwest WNP (Fig. 2b). The associated anomalous ascending motion is favorable for TCG (Wang and Chan 2002).

The large-scale circulations concurring with the active TCG in the southeast WNP are tightly linked to the developing phase of El Niño (Fig. 3a). Specially, the SST warming over the equatorial central-eastern Pacific can, through increasing convective heating, generate pronounced equatorial westerly anomalies in the western Pacific as the Rossby response (Fig. 3a). The meridional shear vorticity of the anomalous westerly wind serves to favor TCG in the southeast WNP. At the upper troposphere, the anomalous anticyclone over the eastern WNP indicates the eastward migration in the tropical upper troposphere trough, which can favor TCG in the southeast WNP by weakening vertical wind shear (Wu et al. 2015; Wang and Wu 2016, 2018b).

\section{b. The northeast WNP}

The favorable large-scale circulation patterns for TCG in the northeast WNP receive relatively less attention due to its weak impacts on Asian countries (Fig. 1). Generally, active TCG in the northeast WNP is associated with anomalous ascending motion and cyclonic circulation, which are well known to be favorable to TCG (Figs. 4a,b; Gray 1968). Actually, the anomalous cyclonic circulation is coupled to the underlying SST 

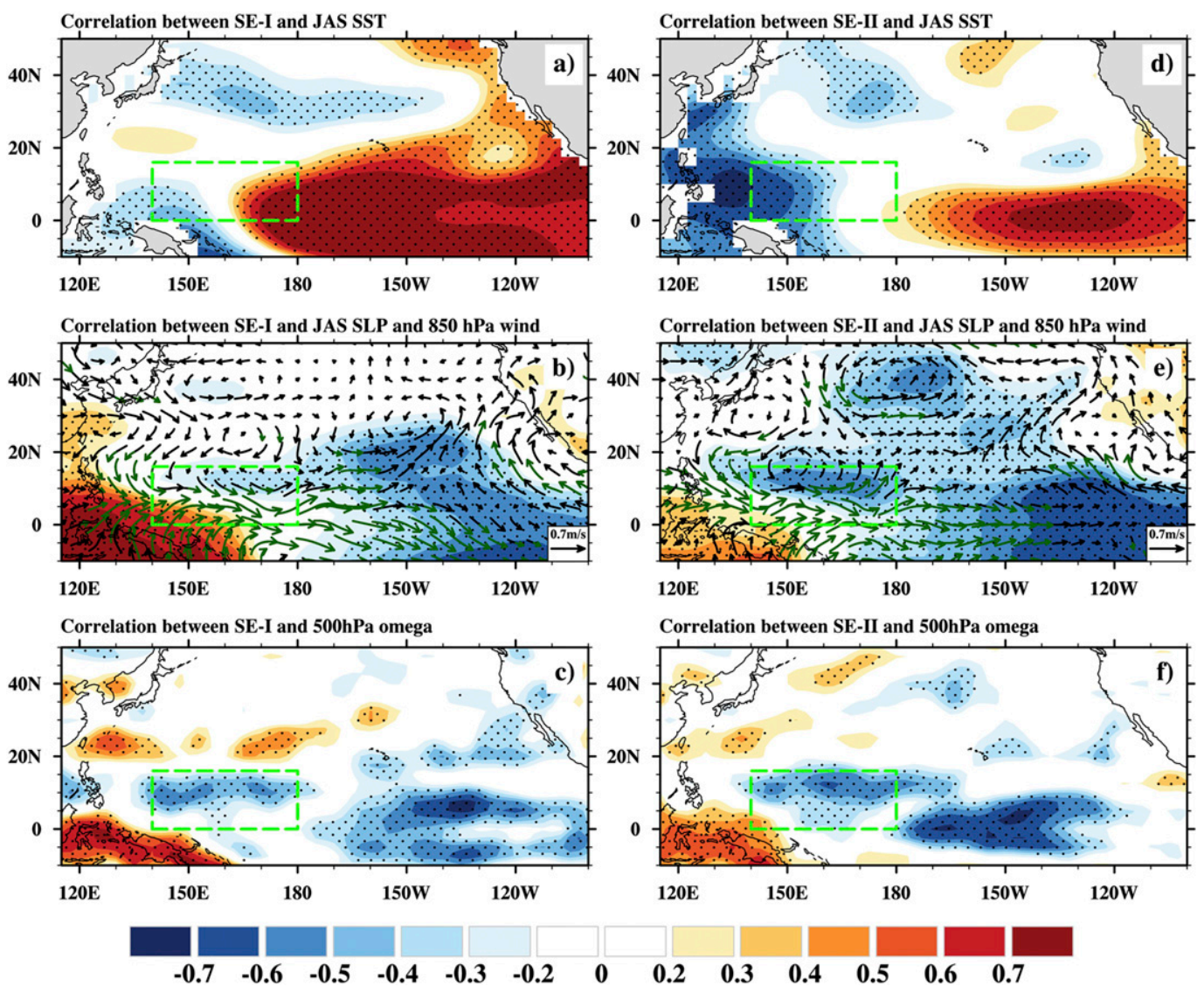

FIG. 10. The lead-lag correlation between predictors for TCG in the southeast WNP and July-September mean large-scale conditions. The correlation maps between predictor SE-I and July-September mean (a) SLP (shadings) and $850-\mathrm{hPa}$ wind (vectors), (b) SST, and (c) 500-hPa omega during 1965-2000. (d)-(f) As in (a)-(c), but for predictor SE-II. The green vectors and dotted areas denote regions with correlation coefficients significant at the $95 \%$ confidence level. The green boxes indicate boundaries of the southeast WNP.

anomalies (Fig. 4a). On the one hand, the anomalous southwesterly wind to the south and southeast of the cyclonic circulation superposed on the mean easterly trade wind decreases total wind speed, suppresses sea surface evaporation and entrainment, and thus warms the SST in a southwest-northeast-tilted band from the tropical eastern WNP to the subtropical eastern Pacific. On the other hand, the anomalous southwesterly wind transports wet and warm air to the northeast of the anomalous cyclonic circulation. Both the SST warming and wet advection increase convective instability and serve to enhance the convection to the southeast of the anomalous cyclonic circulation. The increased convective heating can then generate ascending Rossby waves, which in turn reinforce the anomalous cyclonic circulation (Wang et al. 2000, 2003, 2013; Xiang et al. 2013). Meanwhile, the SST cooling-induced negative convective heating over the equatorial eastern Pacific can stimulate an anomalous low-level anticyclone as a Rossby wave response to its west. The southwesterly wind to the west flank of the anomalous anticyclone can enhance the atmosphere-ocean feedback and then enhance the anomalous cyclonic circulation over the northeast WNP (Wang et al. 2000). Note that the Pacific SST distribution favoring TCG in the northeast WNP resembles that of the PMM (Chiang and Vimont 2004), suggesting that its impact on WNP TC activity comes mainly from the northeast WNP (Zhang et al. 2016a).

\section{c. The southwest WNP}

TCs that form in the southwest WNP exert great impacts on the Philippines and South Asia (Fig. 1; Zhang et al. 2009). However, the favorable large-scale circulation patterns for TCG in this region are still unclear. Here enhanced TCG in the southwest WNP is associated with an anomalous cyclonic anomaly with convergence, which is located to the south of an anticyclonic circulation anomaly and connected to a strong cyclonic anomaly to its east (Fig. 5a). The corresponding 200-hPa winds show evident divergence (Fig. 5b). Moreover, the 

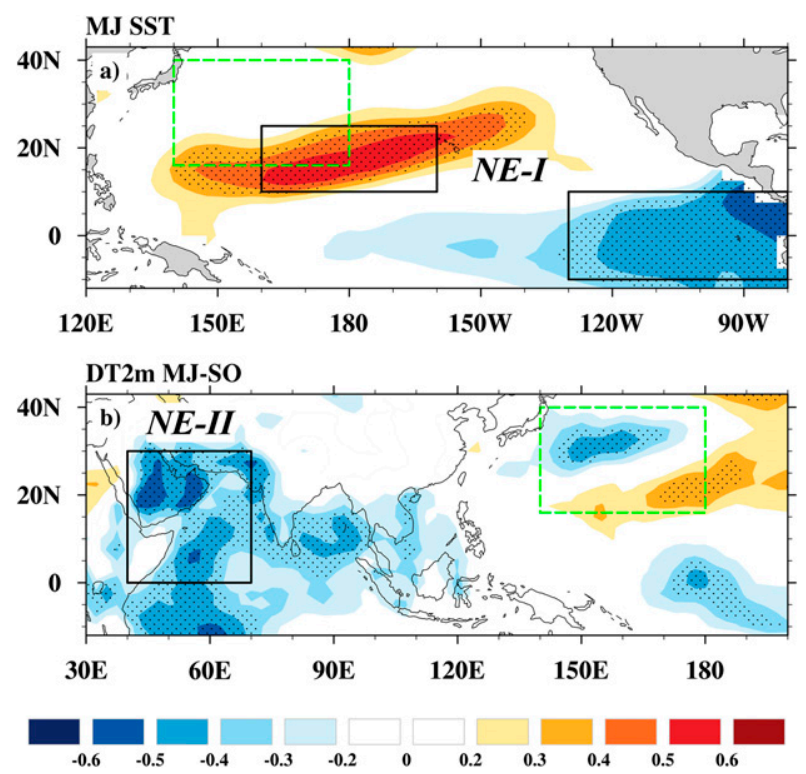

FIG. 11. Predictors for TCG frequency in the northeast WNP. Correlation map between TCG frequency over the northwest WNP and (a) May-June mean SST and (b) 2-m air temperature tendency from September-October to May-June during 1965-2000. Dotted areas denote regions with correlation coefficients significant at the $95 \%$ confidence level. The black boxes represent the location of predictors, and green boxes indicate boundaries of the northeast WNP.

enhanced convective heating over the equatorial eastern Pacific can also contribute the cyclonic shear vorticity over the southwest WNP by generating anomalous equatorial westerlies (Fig. 5a). It should be noted that only the anomalous SST warming over the equatorial central-eastern Pacific can be treated as a forcing, while the SST underlying the two aforementioned anticyclonic circulations may just be a result of atmospheric forcing (Figs. 5a,b; Wang et al. 2005). The different origins of the anomalous circulations indicate the possible importance of including the atmospheric forcing as predictors, which has usually been missed in previous studies (Zhan et al. 2013; Zhang et al. 2018).

\section{d. The South China Sea}

Although most TCs formed in the South China Sea (SCS) usually make landfall in South Asia, their variability sources are still unclear due to the weak relation to the local large-scale conditions (G. Wang et al. 2007). Previous studies did not find significant correlation with the local thermodynamic conditions such as midlevel humidity and SST due to their sufficient climatological value in boreal summer; on the other hand, dynamic factors such as vorticity, large-scale vertical motion, and vertical wind shear are found to play important roles in TCG in the SCS (G. Wang et al.2007). Here we found that these dynamic large-scale conditions are tightly linked to the variation in the upper-level South Asia high (SAH) (Fig. 6). In particular, a weak South Asia high is usually related to the suppressed vertical motion in Yangtze River valley, but enhanced convection in the SCS (Fig. 6a; Wu et al. 2007; Xuan et al. 2011; Wang et al. 2012; Yan et al. 2015), and thus favors SCS TCG. Moreover, the anomalous upper-level westerly wind, which serves to weaken the climatological easterly wind shear, creates a favorable environment for TCG as well (Fig. 6a). At the lower troposphere, a cyclonic circulation is found to be concurrent with the enhanced TCG in the SCS (Fig. 6b). However, there is no significant local SST signal for TCG in the SCS (Fig. 6c), which is consistent with G. Wang et al. (2007).

\section{Physical predictors for individual subregions}

The concurrent large-scale conditions with the active TCG can help us to find out the physically meaningful predictors for TCG in individual subregions. The precursors (prior to July) that can contribute to those concurrent large-scale conditions are considered as potential predictors. Following this, the final predictors are identified by stepwise regression for TCG frequency in each of subregion; some predictors are excluded due to their dependencies on the identified predictors (see section 2 for details).

\section{a. The northwest and southeast WNP}

For TCG frequency in the northwest WNP, two SST predictors are identified. The first one is a persistent predictor, NW-I, which features prominent La Niñalike SST cooling over the equatorial central Pacific during May-June in the active phase of TCG over the northwest WNP (Fig. 7a). Due to the phase-locking feature of ENSO, the SST cooling can be maintained until the ensuing July-September. One may note that there is prominent SST warming in the off-equatorial North Pacific as well, but it gradually dissipates during the La Niña development (Figs. 2a and 8a). The SST cooling-related decreasing Pacific zonal pressure gradient and the suppressed (enhanced) convection in the equatorial central-eastern Pacific (Maritime Continent) serve to enhance the equatorial easterly and western North Pacific subtropical high (Fig. 8b; Wang et al. 2013; Xiang et al. 2013). The subtropical high ridge extends to the Philippines, generating cyclonic shear vorticity to its western flank (Fig. 8b). The cyclonic vorticity can increase the boundary layer Ekman convergence and then enhance the background vertical motion (Fig. 8c), favoring TCG in the northwest WNP (Wang and Chan 2002). The second predictor, NW-II, is an SST tendency predictor from September-October to May-June (Fig. 7b). 

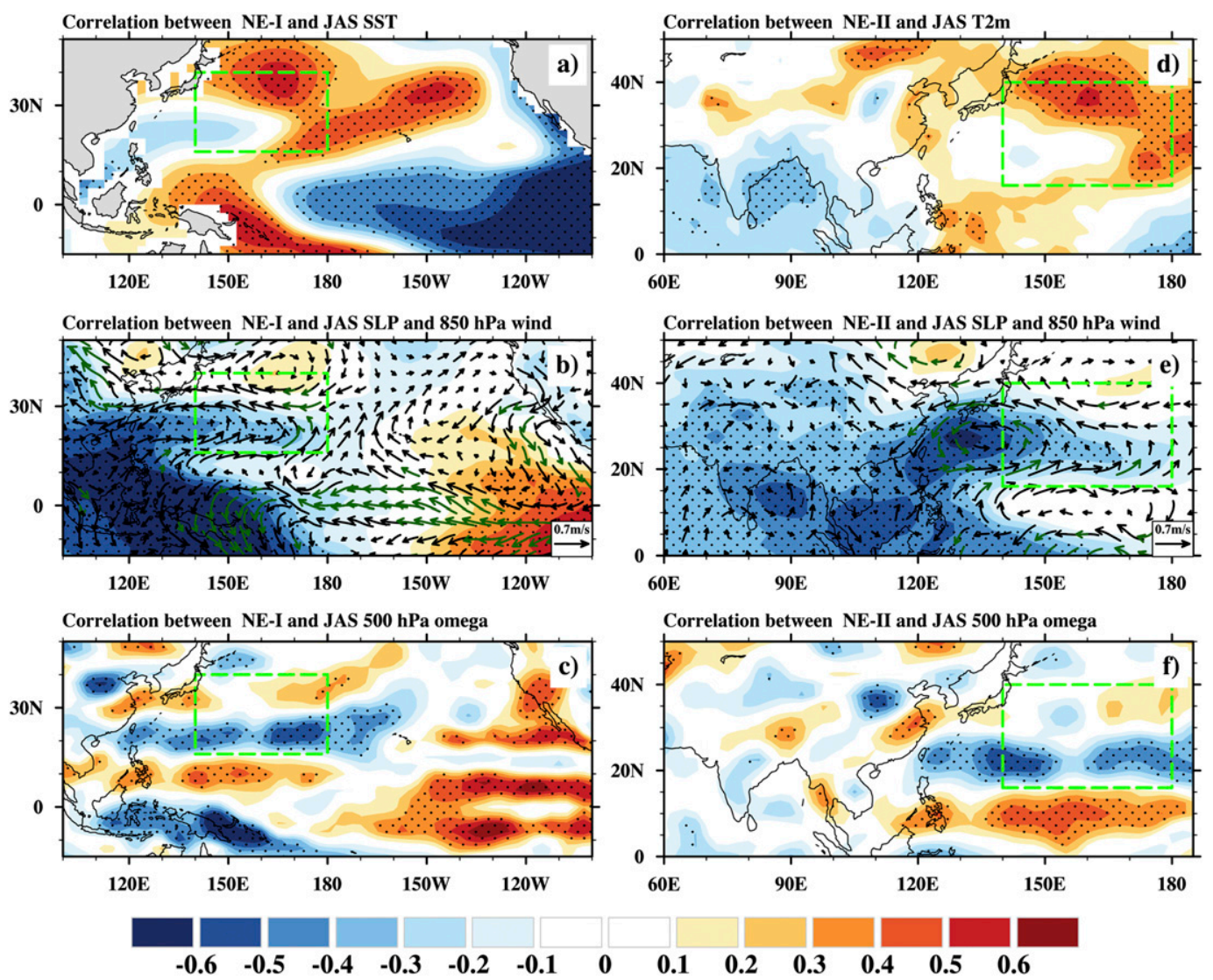

FIG. 12. The lead-lag correlation between predictors for TCG in the northeast WNP and July-September mean large-scale conditions. The correlation maps between predictor NE-I and July-September mean (a) SST, (b) SLP (shadings) and 850-hPa wind (vectors), and (c) 500-hPa omega during 1965-2000. (d)-(f) As in (a)-(c), but for predictor NE-II. The green vectors and dotted areas denote regions with correlation coefficients significant at the $95 \%$ confidence level. The green boxes indicate boundaries of the northeast WNP.

Generally, there is a prominent SST cooling tendency over the north Indian Ocean during the active period of TCG in the northwest WNP (Fig. 7b). The cooling tendency can persist to the following July-September and foreshadows an enhanced Walker circulation and subtropical high via wind-evaporation-SST feedback (Figs. 8d-f). In a similar way, the anomalous subtropical high can enhance the TCG in the northwest WNP by generating cyclonic shear vorticity.

Two ENSO-related SST predictors are identified for the TCG frequency in the southeast WNP (Fig. 9). The first is a persistent predictor, SE-I, which shows prominent SST warming over the equatorial central Pacific during MayJune in the active period of TCG in the southeast WNP. The anomalous SST warming can be sustained to the following July-September due to the phase-locking characteristic of El Niño (Fig. 10a). The El Niño-related enhanced (suppressed) convection in the equatorial centraleastern Pacific (Maritime Continent) shifts monsoon trough eastward, favoring the TCG in southeast WNP by increasing the background vertical motion and cyclonic vorticity (Fig. 10b; Wang and Chan 2002), In addition, at the upper level, the tropical upper troposphere trough migrates to the east, weakening the westerly shear and therefore enhancing the TCG in the southeast WNP (Wu et al. 2015; Wang and Wu 2016, 2018b). The second predictor is the SST tendency from September-October to May-June over the equatorial central Pacific (SE-II; Fig. 9b). The SST tendency can represent the direction of the subsequent evolution of ENSO signal and thus indicate the strength of El Niño and the migrations in largescale circulations in the ensuing July-September period (Figs. 10d-f), which can greatly modify the TCG over the southwest WNP (Lander 1994; Chia and Ropelewski 2002; Wang and Chan 2002; Wang and Wu 2016, 2018b).

\section{b. The northeast WNP}

Two predictors are identified for the TCG frequency in the northwest WNP. The first one is a persistent predictor, NE-I, which shows an SST dipole pattern with 

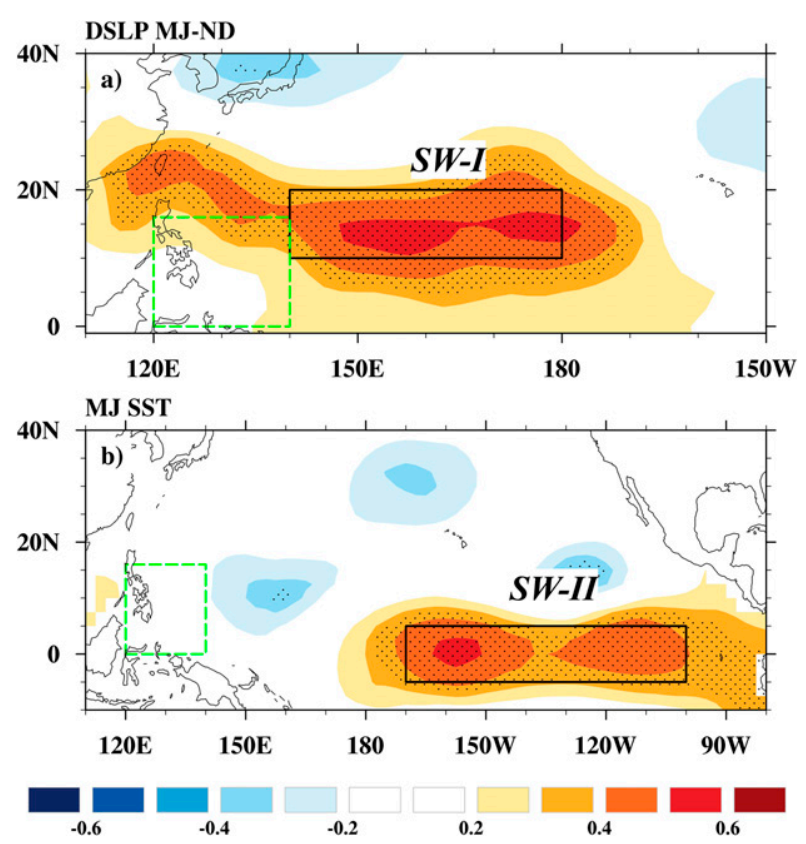

FIG. 13. Predictors for TCG frequency in the southwest WNP. Correlation map between TC genesis frequency in the southwest WNP and (a) SLP tendency from November-December to MayJune (shading) and (b) May-June mean SST during 1965-2000. Dotted areas denote regions with correlation coefficients significant at the $95 \%$ confidence level. The black boxes represent the location of predictors, and green boxes indicate boundaries of the southwest WNP.

cooling in the equatorial eastern Pacific and warming in subtropical North Pacific during the active phase of TCG in the northeast WNP (Fig. 11a). Such a dipole pattern resembles that of the PMM, which can be maintained to the following months through air-sea interaction and sustain an anomalous cyclonic circulation over the northeast WNP (Figs. 12a-c; Chiang and Vimont 2004). On the one hand, the enhanced atmospheric heating in the subtropical North Pacific can stimulate an anomalous cyclonic circulation to its west and north as a Rossby wave response. On the other hand, the surface westerly and southwesterly anomalies to the eastern flank of the anomalous cyclonic circulation can reinforce the underlying SST warming by reducing total wind speed and sea surface evaporation and entrainment cooling (Wang et al. 2000; Chiang and Vimont 2004; Wang et al. 2013; Xiang et al. 2013). Meanwhile, the SST cooling-induced negative convective heating over the equatorial eastern Pacific can stimulate an anomalous low-level anticyclone as a Rossby wave response to its west. The southwesterly to the west flank of anomalous anticyclone can further enhance the atmosphere-ocean feedback and then reinforce the anomalous cyclonic circulation over the northeast WNP (Wang et al. 2000; Chiang and Vimont 2004). The anomalous circulation can further regulate the TC formation in the northeast WNP by modifying the ambient low-level vorticity and vertical wind shear (Zhang et al. 2016a). The second predictor, NE-II, is the 2-m air temperature tendency from September-October to May-June over the northwest Indian Ocean (Fig. 11b). The cooling tendency hints at an SST cooling in the ensuing July-September over the north Indian Ocean (Fig. 12d). The SST cooling can further stimulate a cold Kelvin wave propagating eastward to the WNP, decreasing the surface pressure and leading to an anomalous cyclonic circulation in the northeast WNP (Xie et al. 2009; Zhan et al. 2011b; Wang et al. 2013; Xie et al. 2016; Wang et al. 2017). The opposite is true for an SST warming tendency over the northwest Indian Ocean. Therefore, a cooling (warming) tendency foreshadows an anomalous cyclonic (anticyclonic) circulation over the northeast WNP (Figs. 12d-f), which serves to enhance (suppress) TCG in the northeast WNP.

\section{c. The southwest WNP}

For the southwest WNP, two predictors are identified to predict the TCG frequency in this region (Fig. 13). The first one is the SLP tendency signal from November-December to May-June, SW-I, which is characterized by positive anomalies over the WNP in active years of TCG in the southwest WNP (Fig. 13a). The SLP tendency signal hints at high pressures and anticyclonic circulations in the north WNP and north Australia in the ensuing July-September (Fig. 14a). The SLP tendency-related circulation pattern in JulySeptember is similar to that shown in Fig. 5a, suggesting the possible utility of the SLP predictor in predicting TCG in the southwest WNP. The prominent easterly wind to the south flank of the anticyclonic circulation can increase the cyclonic shear vorticity to its south (i.e., southwest WNP), which tends to favor TC development. Moreover, the two high pressure zones to the north and south sides of the southwest WNP eventually construct a relatively low pressure zone over the southwest WNP, which can strengthen the low-level convergence and thus favor the TCG in this region (Figs. 14b,c). The second predictor is an SST persistent predictor, SW-II, which shows a warming over the equatorial eastern Pacific during May-June in the active phase of TCG in the southwest WNP (Fig. 13b). The SST warming can be sustained to the ensuing July-September because of the phase-locking feature of ENSO. The SST warminginduced atmospheric heating can emanate a cyclonic circulation pair symmetric about the equator as a Rossby wave response. The northern part of the cyclonic pair extends to the southwest WNP and increases 

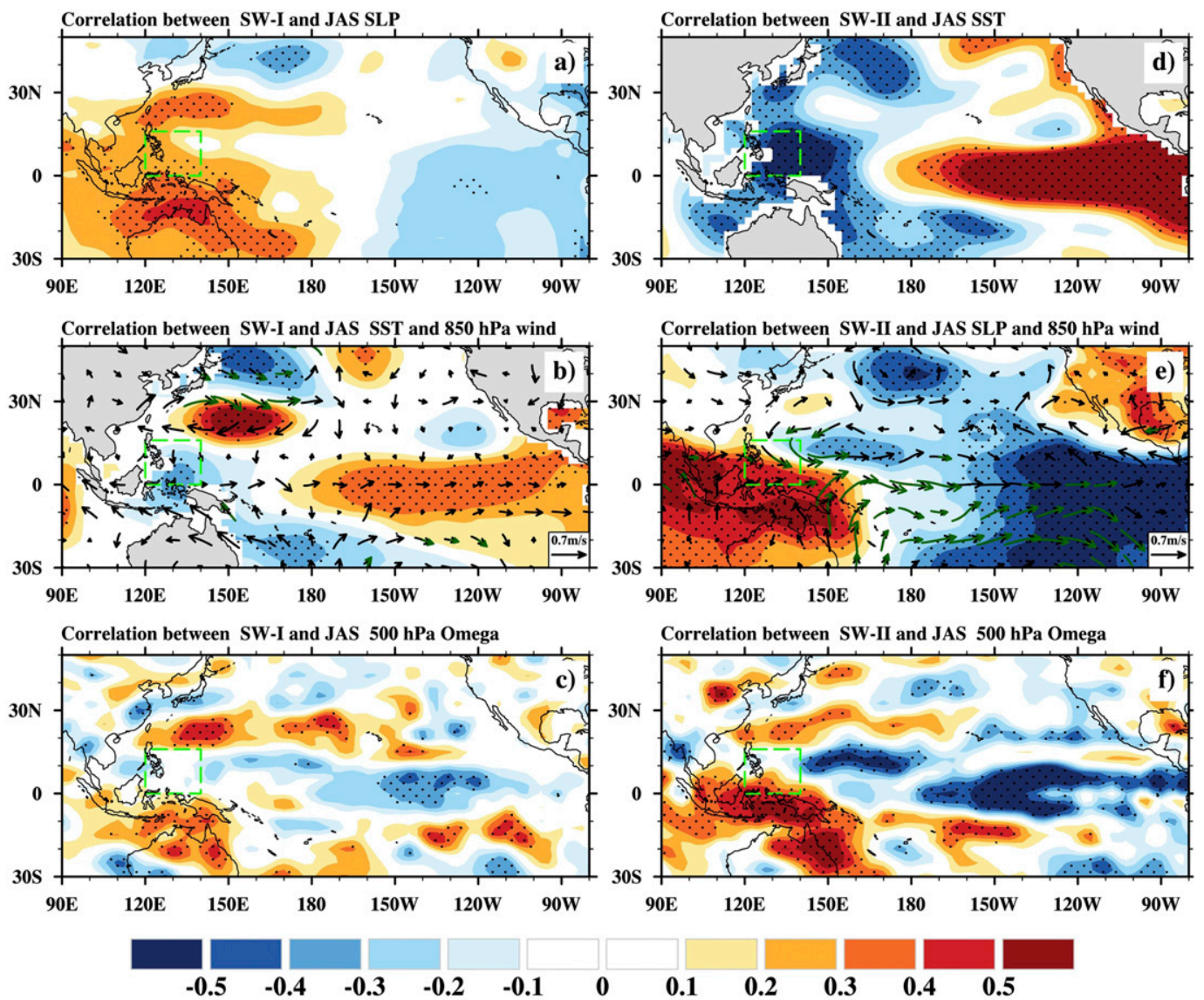

FIG. 14. The lead-lag correlation between predictors for TCG in the southwest WNP and July-September mean large-scale conditions. The correlation maps between predictor SW-I and July-September mean (a) SLP (shadings), (b) SST (shadings) and 850-hPa wind (vectors), and (c) 500-hPa omega during 1965-2000. The correlation maps between predictor SW-II and July-September mean (d) SST (shadings), (e) SLP (shadings) and 850-hPa wind (vectors), and (f) 500-hPa omega during 1965-2000. The green vectors and dotted areas denote regions with correlation coefficients significant at the $95 \%$ confidence level. The green boxes indicate boundaries of the southwest WNP.

cyclonic vorticity in the southwest WNP (Figs. 14e,f). Meanwhile, meridional winds to the west edge of cyclonic circulation pair converge in the southwest WNP, which tends to enhance TCG in the southwest WNP as well.

\section{d. The South China Sea}

Two predictors are identified for the TCG frequency over the South China Sea (Fig. 15). The first one is the June 850-hPa zonal wind over the tropical WNP, which features anomalous easterlies over the Indonesian islands during active years of TCG in the South China Sea (Fig. 15a). In fact, the anomalous easterly wind suggests an inactive monsoon circulation in the South China Sea, which usually corresponds to a weak South Asia high at the upper level (Liu and Zhu 2016). The persistent anomalous easterly wind in the ensuing July-September is consistent with the weakening of the South Asia high, which can favor TCG in the South China Sea by modifying vertical motion, the midlevel humidity, and the low-level vorticity (Figs. 16b,c; Wu et al. 2007; G. Wang et al. 2007; Wang et al. 2012; Yan et al. 2015). The second predictor is SST tendency from March-April to MayJune over the eastern WNP (Fig. 15b). The warming tendency indicates an SST warming in the ensuing JulySeptember. Such an SST warming is concurrent with an anomalous anticyclonic circulation extending from the eastern WNP to East Asia. The cyclonic shear vorticity to the south flank of the anomalous anticyclonic circulation creates a favorable environment for TCG in the SCS. Additionally, the cyclonic vorticity-induced boundary layer Ekman convergence may enhance the ascending motion over the South China Sea as well (Figs. 16d-f). 

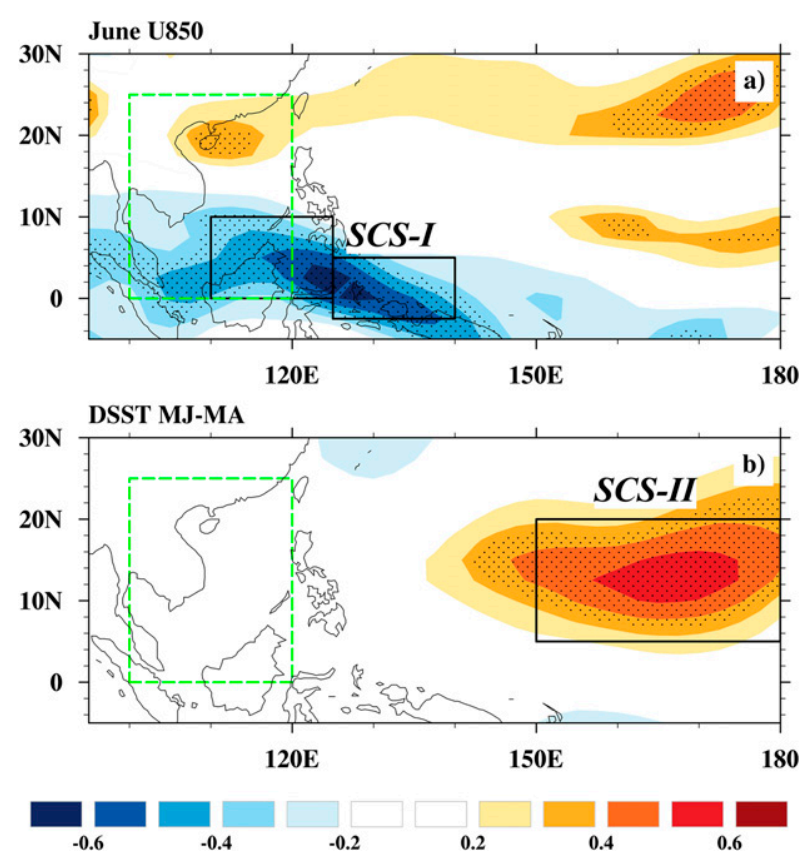

FIG. 15. Predictors for TCG frequency in the South China Sea. Correlation map between TC genesis frequency in the South China Sea and (a) SLP tendency from November-December to MayJune (shading) and (b) SST tendency from September-October to May-June during 1965-2000. Dotted areas denote regions with correlation coefficients significant at the $95 \%$ confidence level. The black boxes represent the location of predictors, and green boxes indicate boundaries of the South China Sea.

Table 1 lists definitions of identified predictors for individual subregions. The different predictors for individual subregions reflect the diverse predictability sources of TCG in individual subregions and further indicates the possible rationality of the region-dependent forecasting strategy.

\section{Predictability and prediction skill for TC genesis in individual subregions}

\section{a. Prediction}

The empirical models derived using the identified predictors listed in Table 1 can reasonably reproduce the interannual variability of TCG frequency in individual subregions. Particularly, the prediction (simulation) for TCG frequency in the northwest WNP, southeast WNP, northeast WNP, southwest WNP, and South China Sea can achieve significant TCC skills of $0.65,0.76,0.62,0.61$, and 0.6, respectively, over the 52-yr period of 1965-2016, suggesting that about $40 \%-60 \%$ of the total variance of TCG frequency can be potentially predicted by using large-scale environmental parameters.

To examine the prediction skills of prediction models, a leave-three-out cross-validated reforecast is performed by taking 3 years out around the predicted year for 1965-2000, and independent forecasts are then made for the remaining 16 years during 2001-16. It is found that both of the cross-validated reforecast and independent forecast for TCG frequency are significantly correlated with observation in each of subregions (Fig. 17). For the northwest WNP, the TCC (MSSS) skill of the cross-validated reforecast during 1965-2000 is 0.62 (0.22), and the independent forecast has significant TCC skill of 0.55 for the most recent 16 years (2001-16) (Fig. 17a). The prediction for the TCG frequency in the southeast WNP exhibits the highest skill among the five subregions, whose TCC (MSSS) skills are $0.76(0.36)$ for 1965-2000 reforecast and 0.68 (0.19) for 2001-16 independent forecast (Fig. 17b). For the northeast WNP, the TCC (MSSS) skill of the cross-validated reforecast during 1965-2000 is $0.58(0.14)$, and the independent forecast for 2001-16 achieves a TCC (MSSS) skill of 0.55 (0.03). The TCC (MSSS) skills for the southwest WNP are $0.51(0.14)$ for the cross-validated reforecast during 1965-2000 and 0.61 (0.2) for the independent forecast in 2001-16. The predicted TCG frequency in the South China Sea also shows valuable skill with TCC (MSSS) skills of 0.62 (0.22) for the 1965-2000 reforecast and 0.61 (0.21) for the 2001-16 independent forecast (Fig. 17e).

The valuable skills in the predicted TCG frequency in individual subregions lend us confidence to further explore the predictability of basinwide TCG frequency over the whole WNP. The predicted TCG frequency over the WNP is simply obtained by adding the predicted TC genesis frequency in all of five subregions (Fig. 17f). Actually, the predicted basinwide TCG frequency also shows significant skill (Fig. 17f). For instance, TCC skill of the independent forecast for 2001-16 achieves 0.76, which shows superior skill to that of traditional statistical approaches (Zhang et al. 2018). The superior prediction skill of the region-dependent strategy both in the basinwide and regional scales, in fact, indicates its higher utility than the traditional prediction approaches, which can only provide us information about basinwide TC activities.

\section{b. Seasonal dependence of the prediction skill}

One may wonder how long the prediction skill can last. Here we found that the favorable large-scale circulation pattern for TCG in each subregion in JulySeptember differs from that in the late season. Such differences are most evident in the SCS and the southwest WNP due to the salient changes in the seasonal/ subseasonal mean large-scale circulation pattern in these two subregions. For example, the $\mathrm{SAH}$, which plays an important role in the SCS TCG in JulySeptember, shifts southward to the Pacific Ocean in the 

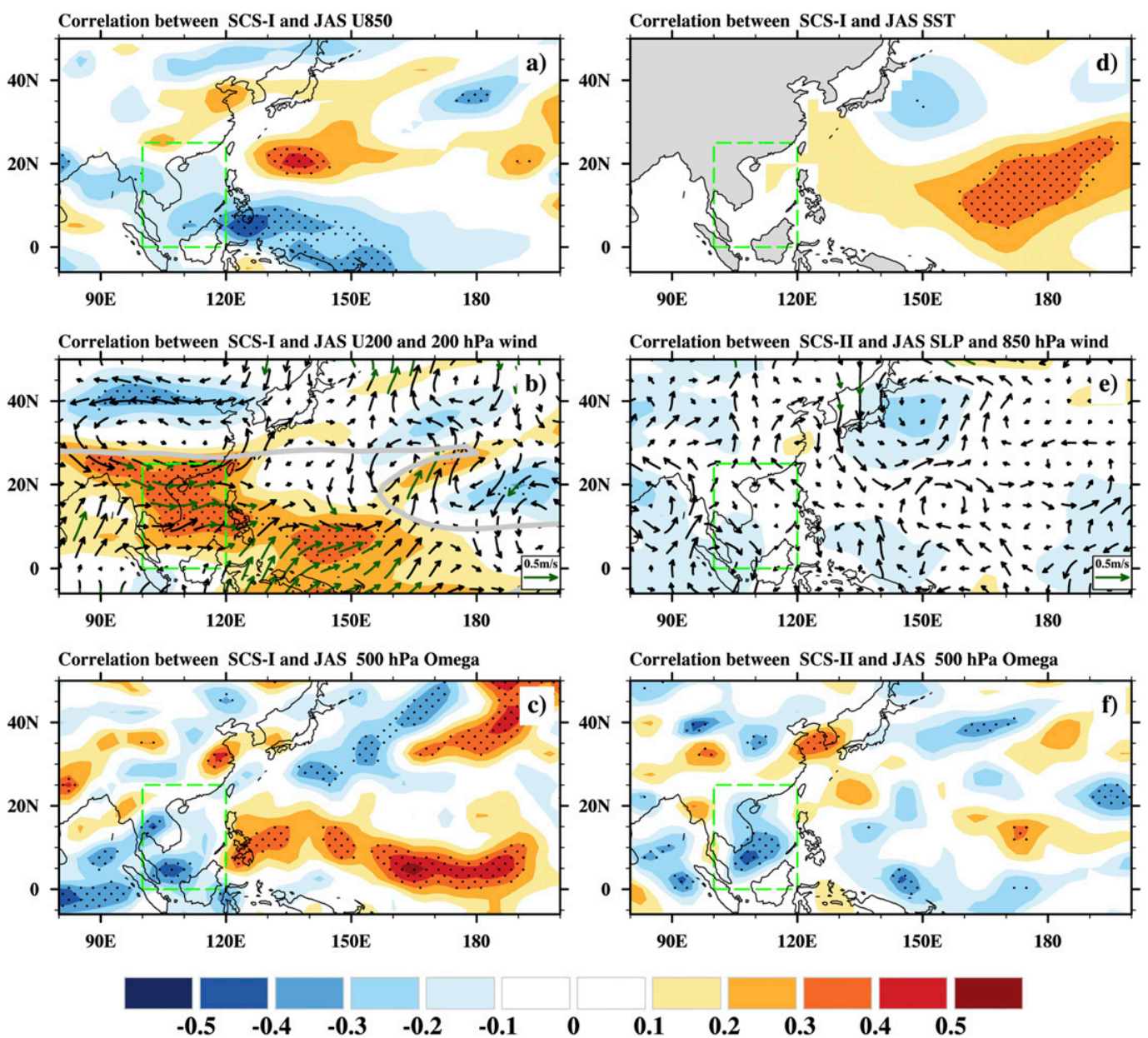

FIG. 16. The lead-lag correlation between predictors for TCG in the South China Sea and July-September mean large-scale conditions. The correlation maps between predictor SCS-I and July-September mean (a) 850-hPa zonal wind (shadings), (b) 200-hPa zonal wind (shadings) and 200-hPa wind (vectors), and (c) 500-hPa omega during 1965-2000. The correlation maps between predictor SCS-II and July-September mean (d) SST (shadings), (e) SLP (shading) and 850-hPa wind (vectors), and (f) 500-hPa omega during 1965-2000. The gray line in (b) shows the zero contour of the climatological 200-hPa zonal wind, which denotes the ridge of the South Asian high. The green vectors and dotted areas denote regions with correlation coefficients significant at the $95 \%$ confidence level. The green boxes indicate boundaries of the South China Sea.

late season and thus exerts relatively weak impact on the SCS TCG. Moreover, some SST predictors are highly coupled with atmosphere through wind-evaporationSST (WES) feedback (Xie and Philander 1994; Wang et al. 2000; Chiang and Vimont 2004; Wang et al. 2005), which is sensitive to the mean circulation pattern. Accordingly, the WES feedback cannot work and maintain the anomalous circulation when the seasonal mean circulation changes (Xie et al. 2016). In other words, the predicting skill highly depends on the seasonal mean large-scale circulation pattern. Figure 18 further shows the seasonal evolution of predicting skills in five subregions. For the SCS, meaningful skill can last to August-October. However, meaningful skill disappears in September-November due to the southward migration in the SAH. Meanwhile, the prediction skill for the southwest WNP experiences an abrupt breakdown in August-October, which is attributable to the salient change in the favorable circulation pattern in October (figure not shown). In contrast, the persistence times of predicting skill in the northwest, southeast, and northeast WNP are relatively longer. The longer persistence in the northwest and southeast WNP can be attributed to the phase-locking feature of ENSO, which plays a vital role in the TCG frequency in the two subregions (Figs. 2 and 3). For the northeast WNP, two predictors are highly coupled with atmosphere thorough windevaporation feedback (Xie and Philander 1994; Wang 
TABLE 1. Definitions of predictors for TCG in individual subregions.

\begin{tabular}{|c|c|c|}
\hline Name & Definition & Meaning \\
\hline NW-I & $\begin{array}{l}\text { May-June mean SST over } \\
5^{\circ} \mathrm{S}-10^{\circ} \mathrm{N}, 180^{\circ}-130^{\circ} \mathrm{W}\end{array}$ & $\begin{array}{l}\text { Central Pacific SST } \\
\text { predictor }\end{array}$ \\
\hline NW-II & $\begin{array}{l}\text { May-June minus October- } \\
\text { November SST tendency } \\
\text { over } 5^{\circ} \mathrm{S}-20^{\circ} \mathrm{N}, 50^{\circ}-100^{\circ} \mathrm{E}\end{array}$ & Indian Ocean SST predictor \\
\hline SE-I & $\begin{array}{l}\text { May-June mean SST over } \\
10^{\circ} \mathrm{S}-10^{\circ} \mathrm{N}, 180^{\circ}-130^{\circ} \mathrm{W}\end{array}$ & $\begin{array}{l}\text { Central Pacific SST } \\
\text { predictor }\end{array}$ \\
\hline SE-II & $\begin{array}{l}\text { May-June minus October- } \\
\text { November SST tendency } \\
\text { over } 10^{\circ} \mathrm{S}-10^{\circ} \mathrm{N}, 180^{\circ}- \\
220^{\circ} \mathrm{E}\end{array}$ & $\begin{array}{l}\text { Central Pacific SST } \\
\text { tendency predictor }\end{array}$ \\
\hline NE-I & $\begin{array}{l}\text { May-June mean SST }\left(10^{\circ} \mathrm{S}-\right. \\
\left.10^{\circ} \mathrm{N}, 130^{\circ}-80^{\circ} \mathrm{W}\right) \text { minus } \\
\text { SST }\left(10^{\circ}-25^{\circ} \mathrm{N}, 160^{\circ} \mathrm{E}-\right. \\
\left.160^{\circ} \mathrm{W}\right)\end{array}$ & Pacific dipole SST predictor \\
\hline NE-II & $\begin{array}{l}\text { May-June minus } \\
\text { September-October } 2-\mathrm{m} \\
\text { air temperature tendency } \\
\text { over } 0^{\circ}-30^{\circ} \mathrm{N}, 40^{\circ}-70^{\circ} \mathrm{E}\end{array}$ & $\begin{array}{l}\text { West Indian Ocean } \mathrm{T} 2 \mathrm{~m} \\
\text { tendency predictor }\end{array}$ \\
\hline SW-I & $\begin{array}{l}\text { May-June minus } \\
\text { November-December } \\
\text { SLP tendency over } 10^{\circ}- \\
20^{\circ} \mathrm{N}, 140^{\circ} \mathrm{E}-180^{\circ}\end{array}$ & $\begin{array}{l}\text { WNP SLP tendency } \\
\text { predictor }\end{array}$ \\
\hline SW-II & $\begin{array}{l}\text { May-June mean SST over } \\
5^{\circ} \mathrm{S}-5^{\circ} \mathrm{N}, 170^{\circ}-100^{\circ} \mathrm{W}\end{array}$ & $\begin{array}{l}\text { Central Pacific SST } \\
\text { predictor }\end{array}$ \\
\hline SCS-I & $\begin{array}{l}\text { June } 850-\mathrm{hPa} \text { zonal wind } \\
\text { over } 0^{\circ}-10^{\circ} \mathrm{N}, 110^{\circ}-125^{\circ} \mathrm{E} \\
\text { and } 2.5^{\circ} \mathrm{S}-7.5^{\circ} \mathrm{N}, 125^{\circ}- \\
140^{\circ} \mathrm{E}\end{array}$ & $\begin{array}{l}\text { Indonesia zonal wind } \\
\text { predictor }\end{array}$ \\
\hline SCS-II & $\begin{array}{l}\text { May-June minus March- } \\
\text { April SST tendency over } \\
5^{\circ} \mathrm{N}-20^{\circ} \mathrm{N}, 150^{\circ} \mathrm{E}-180^{\circ}\end{array}$ & $\begin{array}{l}\text { Eastern WNP SST } \\
\text { tendency predictor }\end{array}$ \\
\hline
\end{tabular}

et al. 2000; Chiang and Vimont 2004). Therefore, the prediction skill gradually decreases with the retreat of summer monsoon. On a basinwide scale, the prediction models can obtain a meaningful skill for July-October (Fig. 18). Table 2 shows the predicting results with target season of July-October. It can be seen that the results are generally similar to those in July-September except for the southwest WNP due to its salient change in the favorable large-scale pattern in October. It means that the determinate factors for TCG in the southwest WNP are highly season dependent, making it is difficult to predict the TCG in the southwest WNP for a long season.

\section{Summary \\ a. Conclusions}

Traditional statistical seasonal forecasting approaches for TC activity over the WNP take TCG frequency over the whole WNP as the targeted predictands. However, TCG over the WNP displays distinct regional features, and the basinwide TC metrics usually act as a poorer indicator than those in WNP subregions. The utility of the forecast products would, therefore, be enhanced if seasonal TC activity on scales finer than basinwide could be skillfully predicted (Vecchi et al. 2014). This motivates us to establish a regional-dependent seasonal forecasting framework for TCG frequency over the WNP.

We have identified the large-scale circulation patterns and underlying boundary conditions co-occurring with active TCG in individual subregions. Besides the wellknown ENSO-related seesaw relationship between the TCG frequency over the southeast and northwest WNP, we find that the enhanced TCG in the northeast WNP is associated with a pronounced cyclonic circulation anomaly, which is maintained through interaction between the cyclonic circulation and the underlying tripole SST anomalies in the northern Indo-Pacific. The anomalous cyclonic circulation can favor the TCG by modifying ambient low-level vorticity and vertical wind shear. For the southwest WNP, the favorable circulations and boundary conditions for TCG are the two high pressure regions to the two sides of the southwest WNP and the SST warming over the equatorial central-eastern Pacific. The high pressure-associated circulations and the SST warming-related anomalous equatorial westerly wind can generate cyclonic vorticity and enhance the convergence in the southwest WNP, and thus favor the TCG. For the South China Sea, we found that a weak South Asia high can contribute to the active TCG by enhancing the vertical motion and weakening the climatological easterly wind shear in the northern South China Sea.

Based on the simultaneous large-scale circulation and boundary conditions, the precursors that can contribute to those concurrent large-scale conditions are considered as potential predictors. Several physically meaningful predictors are identified for each subregion. We found that ENSO precursors predict TCG frequency over the northwest and southeast WNP, while the MayJune mean dipole SST pattern that resembles the PMM and the 2-m temperature tendency over the west Indian Ocean are found to be useful to predict TCG frequency in the northeast WNP. Seasonal prediction for TCG frequency in the southwest WNP and the South China Sea usually shows limited skills. Here we found that the SLP tendency over the northern WNP and SST over the equatorial central-eastern Pacific can provide predictive information for TCG in the southwest WNP. For TCG in the South China Sea, the June 850-hPa wind over Indonesia and SST tendency over the eastern WNP can be useful precursors. The possible causative linkages between identified predictors and predictands are also discussed. 

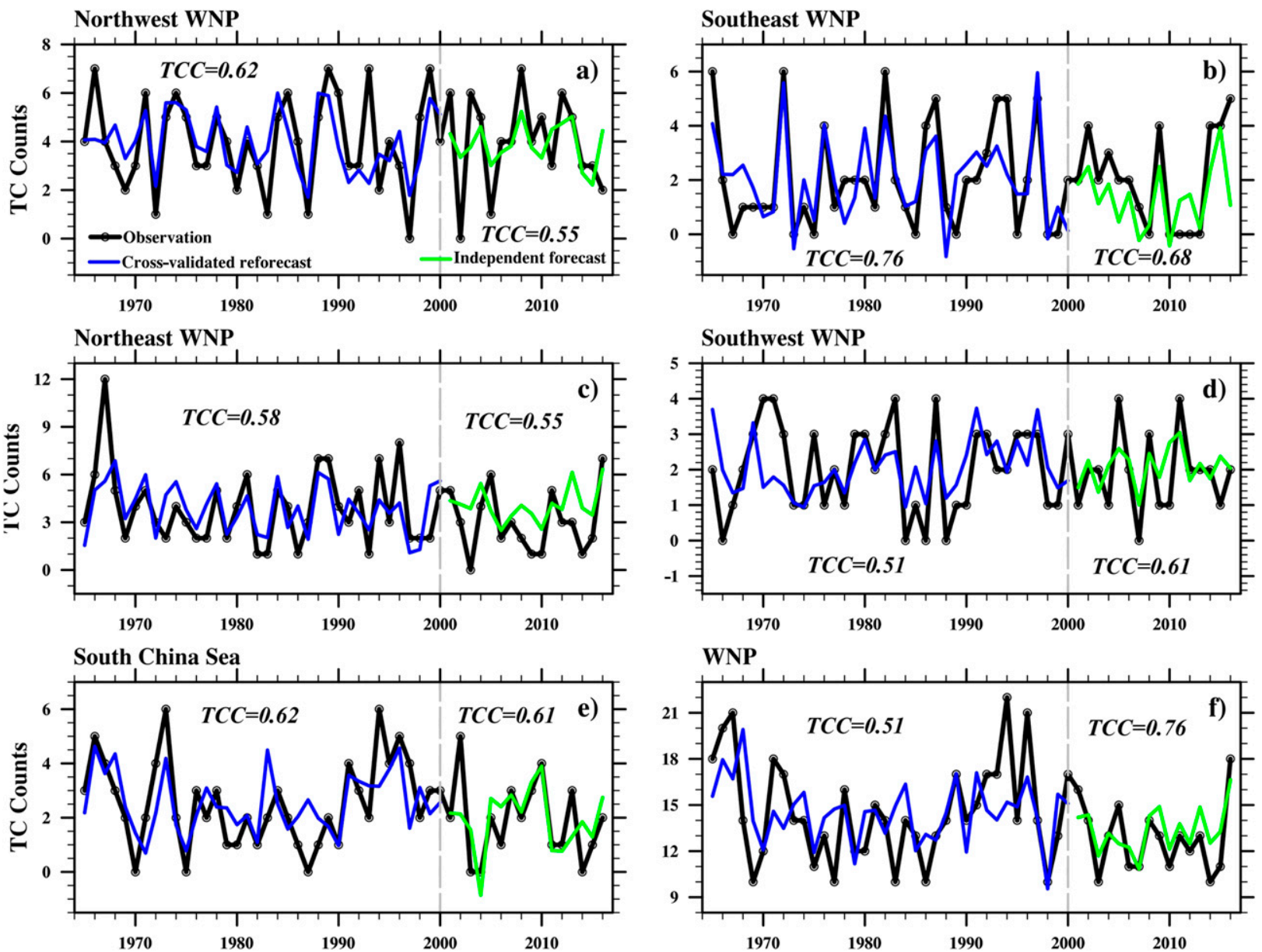

FIG. 17. Predictability and prediction skill for the TCG frequency in individual subregions and the whole WNP. Time series of TC counts over the (a) northwest WNP, (b) southeast WNP, (c) northeast WNP, (d) southwest WNP, (e) South China Sea, and (f) WNP obtained from the JTWC best track (black line), cross-validated reforecast (blue line), and prediction (green line) from 1965 to 2016. The gray dashed lines separate the training and prediction period. The corresponding TCC is shown in each panel.

To investigate the predictability of TCG frequency in individual subregions, a set of empirical prediction models is established using the aforementioned predictors. It is found that the physical-empirical models can reasonably reproduce the interannual variability of TCG frequency in each of five subregions. Particularly, the prediction (simulation) for TCG frequency in the northwest WNP, southeast WNP, northeast WNP, southwest WNP, and South China Sea regions can achieve significant TCC skills of $0.65,0.76,0.62,0.61$, and 0.6, respectively, over the 52-yr period of 1965-2016. Moreover, we used data from 1965 to 2000 as a training period to build the prediction equation and performed a $16-\mathrm{yr}$ independent prediction. The independent reforecast for TCG frequency during 2001-16 over the northwest WNP, southeast WNP, northeast WNP, southwest WNP, and the South China Sea achieves significant TCC skill of $0.55,0.68,0.55,0.61$, and 0.61 , respectively. Surprisingly, their sum (i.e., the predicted TCG frequency for the whole WNP) also demonstrates superior predicting skill with a TCC skill of 0.76 for the independent forecast period of 2001-16. The superior skills both in the basinwide and regional scales of the region-dependent strategy indicate its higher utility compared to the traditional statistical prediction approach, which only provides us with TC information for the whole basin.

\section{b. Discussion}

TCG in the vast WNP experiences distinct regional features (Wang and Chan 2002; Kim et al. 2010), and it does not experience unified variations even in response to the same large-scale forcing. The distinct regional characteristic in TCG over the WNP should be considered when establishing prediction models. The proposed region-dependent forecasting strategy can be an 


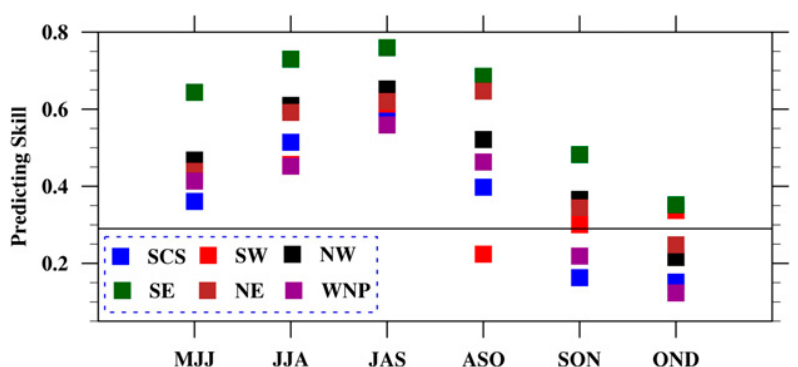

FIG. 18. Correlation coefficient of predicted and observed seasonal TC genesis frequency in the SCS (blue squares), southwest WNP (red squares), northwest WNP (black squares), southeast WNP (green squares), northeast WNP (brown squares), and WNP (purple squares) during 1965-2016. The black line denotes the 95\% significance level.

effective pathway to yield higher skill and utility than the traditional statistical prediction approaches.

Although valuable prediction skills in the basinwide and regional TCG frequency are found in the regiondependent forecasting strategy, some limitations exist in this approach. The first is the possible nonstationary relationship between the predictor and predictand, which is a common limitation for empirical prediction method. For instance, the relation between the PMM and TCG frequency in the northeast WNP weakens in the recent two decades, making the prediction skill comparatively low in the independent forecast during 2000-16 (figure is not shown). Moreover, the TCC skill for the TCG in the WNP during 1965-2000 is relatively weaker than for each subregion, but it shows better skill than those in subregions for 2001-16. This means that the predicting errors in each subregion may be accumulated during 1965-2000 but offset each other during 2001-16. This result indicates that an unstable relationship of predicting errors in individual cases may play a role in overall predicting skills. Second, the proposed physical linkages between the predictors and predictands are largely based on physical reasoning. While the involved physical processes of how the selected predictors affect TCG in the southeast and northwest WNP have been well established by previous studies, how the selected predictors influence TCG in

TABLE 2. Correlation coefficients between the observed TC genesis frequency and cross-validated reforecast (1965-99) and prediction (2000-16) during July-October in individual subregions and the WNP. The significant correlations are bold.

\begin{tabular}{lllllll}
\hline \hline & SCS & SW & NW & SE & NE & WNP \\
\hline $1965-99$ & $\mathbf{0 . 5 1}$ & 0.1 & $\mathbf{0 . 6 1}$ & $\mathbf{0 . 7 7}$ & $\mathbf{0 . 5 8}$ & $\mathbf{0 . 4 7}$ \\
$2000-16$ & $\mathbf{0 . 5 9}$ & 0.38 & $\mathbf{0 . 5 2}$ & $\mathbf{0 . 6 9}$ & $\mathbf{0 . 4 9}$ & $\mathbf{0 . 6 8}$ \\
\hline
\end{tabular}

northeast and southwest WNP and the South China Sea still requires more work to examine the detailed physical processes. Numerical models provide us with a promising pathway to resolve these issues. Additionally, definitions of subregions are originally designed to understand the ENSO impacts on TCG over the WNP (Wang and Chan 2002), which may not be most suitable for representing the regional features of TCG on the interannual time scale. The predictable mode analysis may be a more viable strategy to portray the regional features as done in Wang et al. (2015a), and we intend to explore this issue in a future study.

Acknowledgments. This study was jointly supported by the National Natural Science Foundation of China (Grants 41705060, 41420104002, 41730961, and 41675072), the Natural Science Foundation of Jiangsu Province (BK20170941) and the National Key Research and Development Program of China (Grant 2016YFA0600401). This is the NUIST-Earth System Modeling Center (ESMC) publication number 286 and School of Ocean and Earth Science and Technology (SOEST) publication number 10839.

\section{REFERENCES}

Camargo, S. J., A. G. Barnston, P. J. Klotzbach, and C. W. Landsea, 2007a: Seasonal tropical cyclone forecasts. WMO Bull., 56, 297-309.

— , K. A. Emanuel, and A. H. Sobel, 2007b: Use of a genesis potential index to diagnose ENSO effects on tropical cyclone genesis. J. Climate, 20, 4819-4834, https://doi.org/10.1175/ JCLI4282.1.

— A. H. Sobel, A. G. Barnston, and P. J. Klotzbach, 2010: The influence of natural climate variability on tropical cyclones, and seasonal forecasts of tropical cyclone activity. Global Perspectives on Tropical Cyclones, J. C. L. Chan and J. D. Kepert, Eds., World Scientific, 325-360.

Camp, J., M. Roberts, C. Maclachlan, E. Wallace, L. Hermanson, A. Brookshaw, A. Arribas, and A. A. Scaife, 2015: Seasonal forecasting of tropical storms using the Met Office GloSea5 seasonal forecast system. Quart. J. Roy. Meteor. Soc., 141, 2206-2219, https://doi.org/10.1002/qj.2516.

Chan, J. C. L., 2005: Interannual and interdecadal variations of tropical cyclone activity over the western North Pacific. Meteor. Atmos. Phys., 89, 143-152, https://doi.org/10.1007/ s00703-005-0126-y.

- 2006: Comment on "Changes in tropical cyclone number, duration, and intensity in a warming environment." Science, 311, 1713, https://doi.org/10.1126/science.1121522.

_ J. Jhi, and C.-M. Lam, 1998: Seasonal forecasting of tropical cyclone activity over the western North Pacific and the South China Sea. Wea. Forecasting, 13, 997-1004, https://doi.org/ 10.1175/1520-0434(1998)013<0997:SFOTCA > 2.0.CO;2.

_ J.-E. Shi, and K. S. Liu, 2001: Improvements in the seasonal forecasting of tropical cyclone activity over the western North Pacific. Wea. Forecasting, 16, 491-498, https://doi.org/10.1175/ 1520-0434(2001)016<0491:IITSFO > 2.0.CO;2. 
Chen, D., H. Wang, J. Liu, and G. Li, 2015: Why the spring North Pacific Oscillation is a predictor of typhoon activity over the western North Pacific. Int. J. Climatol., 35, 3353-3361, https:// doi.org/10.1002/joc.4213.

Chen, J.-H., and S.-J. Lin, 2013: Seasonal predictions of tropical cyclones using a $25-\mathrm{km}$-resolution general circulation model. J. Climate, 26, 380-398, https://doi.org/10.1175/JCLI-D-1200061.1

Chia, H. H., and C. F. Ropelewski, 2002: The interannual variability in the genesis location of tropical cyclones in the northwest Pacific. J. Climate, 15, 2934-2944, https://doi.org/ 10.1175/1520-0442(2002)015<2934:TIVITG >2.0.CO;2.

Chiang, J. C. H., and D. J. Vimont, 2004: Analogous Pacific and Atlantic meridional modes of tropical atmosphere-ocean variability. J. Climate, 17, 4143-4158, https://doi.org/10.1175/JCLI4953.1.

Du, Y., L. Yang, and S.-P. Xie, 2011: Tropical Indian Ocean influence on northwest Pacific tropical cyclones in summer following strong El Niño. J. Climate, 24, 315-322, https://doi.org/ 10.1175/2010JCLI3890.1.

Emanuel, K. A., and D. S. Nolan, 2004: Tropical cyclone activity and the global climate system. 26th Conf. on Hurricanes and Tropical Meteorology, Miami, FL, Amer. Meteor. Soc., 10A.2, https://ams.confex.com/ams/26HURR/techprogram/paper_ 75463.htm.

Fan, K., and H. Wang, 2009: A new approach to forecasting typhoon frequency over the western North Pacific. Wea. Forecasting, 24, 974-986, https://doi.org/10.1175/2009WAF2222194.1.

Gray, W. M., 1968: Global view of the origin of tropical disturbances and storms. Mon. Wea. Rev., 96, 669-700, https://doi.org/ 10.1175/1520-0493(1968)096<0669:GVOTOO >2.0.CO;2.

__ 1984: Atlantic seasonal hurricane frequency. Part I: El Niño and $30 \mathrm{mb}$ quasi-biennial oscillation influences. Mon. Wea. Rev., 112, 1649-1668, https://doi.org/10.1175/1520-0493(1984) 112<1649:ASHFPI $>2.0 . \mathrm{CO} ; 2$

Ho, C.-H., J. Kim, H. Kim, C. Sui, and D. Gong, 2005: Possible influence of the Antarctic Oscillation on tropical cyclone activity in the western North Pacific. J. Geophys. Res., 110, D19104, https://doi.org/10.1029/2005JD005766.

Huang, B., and Coauthors, 2015: Extended reconstructed sea surface temperature version 4 (ERSST.v4). Part I: Upgrades and intercomparisons. J. Climate, 28, 911-930, https://doi.org/ 10.1175/JCLI-D-14-00006.1.

Huo, L., P. Guo, S. N. Hameed, and D. Jin, 2015: The role of tropical Atlantic SST anomalies in modulating western North Pacific tropical cyclone genesis. Geophys. Res. Lett., 42, 23782384, https://doi.org/10.1002/2015GL063184.

Kalnay, E., and Coauthors, 1996: The NCEP/NCAR 40-Year Reanalysis Project. Bull. Amer. Meteor. Soc., 77, 437-471, https:// doi.org/10.1175/1520-0477(1996)077<0437:TNYRP>2.0.CO;2.

Kim, H.-S., C.-H. Ho, P.-S. Chu, and J.-H. Kim, 2009: Seasonal prediction of summertime tropical cyclone activity over the East China Sea using the least absolute deviation regression and the Poisson regression. Int. J. Climatol., 30, 210-219, https://doi.org/10.1002/JOC.1878.

Kim, J.-H., C.-H. Ho, and P.-S. Chu, 2010: Dipolar redistribution of summertime tropical cyclone genesis between the Philippine Sea and the northern South China Sea and its possible mechanisms. J. Geophys. Res., 115, D06104, https://doi.org/ 10.1029/2009JD012196.

Kim, O.-Y., H.-M. Kim, M.-I. Lee, and Y.-M. Min, 2017: Dynamical-statistical seasonal prediction for western North Pacific typhoons based on APCC multi-models. Climate Dyn., 48, 71-88, https://doi.org/10.1007/s00382-016-3063-1.
King, D., J. Davidson, and L. Anderson-Berry, 2010: Disaster mitigation and societal impacts. Global Perspectives on Tropical Cyclones: From Science to Mitigation, J. C. L. Chan and J. D. Kepert, Eds., World Scientific, 409-436.

Kossin, J. P., 2017: Hurricane intensification along United States coast suppressed during active hurricane periods. Nature, 541, 390-393, https://doi.org/10.1038/nature20783.

Lander, M. A., 1994: An exploratory analysis of the relationship between tropical storm formation in the western North Pacific and ENSO. Mon. Wea. Rev., 122, 636-651, https://doi.org/ 10.1175/1520-0493(1994)122<0636:AEAOTR >2.0.CO;2.

Lee, J.-Y., S.-S. Lee, B. Wang, K.-J. Ha, and J.-G. Jhun, 2013: Seasonal prediction and predictability of the Asian winter temperature variability. Climate Dyn., 41, 573-587, https:// doi.org/10.1007/s00382-012-1588-5.

Liu, B., and C. Zhu, 2016: A possible precursor of the South China Sea summer monsoon onset: Effect of the South Asian high. Geophys. Res. Lett., 43, 11 072-11 079, https://doi.org/10.1002/ 2016GL071083.

Lu, M.-M., P.-S. Chu, and Y.-C. Lin, 2010: Seasonal prediction of tropical cyclone activity near Taiwan using the Bayesian multivariate regression method. Wea. Forecasting, 25, 1780 1795, https://doi.org/10.1175/2010WAF2222408.1.

Manganello, J. V., and Coauthors, 2016: Seasonal forecasts of tropical cyclone activity in a high-atmospheric-resolution coupled prediction system. J. Climate, 29, 1179-1200, https:// doi.org/10.1175/JCLI-D-15-0531.1.

Michaelsen, J., 1987: Cross-validation in statistical climate forecast models. J. Climate Appl. Meteor., 26, 1589-1600, https://doi.org/ 10.1175/1520-0450(1987)026<1589:CVISCF $>2.0 . C O ; 2$.

Murakami, H., and B. Wang, 2010: Future change of North Atlantic tropical cyclone tracks: Projection by a $20-\mathrm{km}-\mathrm{mesh}$ global atmospheric model. J. Climate, 23, 2699-2721, https:// doi.org/10.1175/2010JCLI3338.1.

Murphy, A. H., 1988: Skill scores based on the mean square error and their relationships to the correlation coefficient. Mon. Wea. Rev., 116, 2417-2424, https://doi.org/10.1175/15200493(1988)116<2417:SSBOTM $>2.0$.CO;2.

Nicholls, N., 1979: A possible method for predicting seasonal tropical cyclone activity in the Australian region. Mon. Wea. Rev., 107, 1221-1224, https://doi.org/10.1175/1520-0493(1979) 107<1221:APMFPS >2.0.CO;2.

Peduzzi, P., B. Chatenoux, H. Dao, A. De Bono, C. Herold, J. Kossin, F. Mouton, and O. Nordbeck, 2012: Global trends in tropical cyclone risk. Nat. Climate Change, 2, 289-294, https:// doi.org/10.1038/nclimate1410.

Pielke, R. A., J. Gratz, C. W. Landsea, D. Collins, M. A. Saunders, and R. Musulin, 2008: Normalized hurricane damage in the United States: 1900-2005. Nat. Hazards Rev., 9, 29-42, https:// doi.org/10.1061/(ASCE)1527-6988(2008)9:1(29).

Tao, L., L. Wu, Y. Wang, and J. Yang, 2012: Influence of tropical Indian Ocean warming and ENSO on tropical cyclone activity over the western North Pacific. J. Meteor. Soc. Japan, 90, 127 144, https://doi.org/10.2151/jmsj.2012-107.

Vecchi, G. A., and Coauthors, 2014: On the seasonal forecasting of regional tropical cyclone activity. J. Climate, 27, 7994-8016, https://doi.org/10.1175/JCLI-D-14-00158.1.

Wang, B., and J. C. L. Chan, 2002: How strong ENSO events affect tropical storm activity over the western North Pacific. J. Climate, 15, 1643-1658, https://doi.org/10.1175/1520-0442(2002)015<1643: HSEEAT $>2.0 . \mathrm{CO} ; 2$

, R. Wu, and X. Fu, 2000: Pacific-East Asian teleconnection: How does ENSO affect East Asian climate? J. Climate, 13, 
1517-1536, https://doi.org/10.1175/1520-0442(2000)013<1517: PEATHD $>2.0 . \mathrm{CO} ; 2$.

,-- , and T. Li, 2003: Atmosphere-warm ocean interaction and its impacts on Asian-Australian monsoon variation. J. Climate, 16, 1195-1211, https://doi.org/10.1175/15200442(2003)16<1195:AOIAII >2.0.CO;2.

—-, Q. Ding, X. Fu, I.-S. Kang, K. Jin, J. Shukla, and F. Doblas-Reyes, 2005: Fundamental challenge in simulation and prediction of summer monsoon rainfall. Geophys. Res. Lett., 32, L15711, https://doi.org/10.1029/ 2005 GL022734.

—, Y. Yang, Q.-H. Ding, H. Murakami, and F. Huang, 2010: Climate control of the global tropical storm days (1965-2008). Geophys. Res. Lett., 37, L07704, https://doi.org/10.1029/ 2010 GL042487.

__ B. Xiang, and J.-Y. Lee, 2013: Subtropical high predictability establishes a promising way for monsoon and tropical storm predictions. Proc. Natl. Acad. Sci. USA, 110, 2718-2722, https://doi.org/10.1073/pnas.1214626110.

_- J.-Y. Lee, and B. Xiang, 2015a: Asian summer monsoon rainfall predictability: A predictable mode analysis. Climate Dyn., 44, 61-74, https://doi.org/10.1007/s00382-014-2218-1.

—, B. Xiang, J. Li, P. J. Webster, M. N. Rajeevan, J. Liu, and K.-J. Ha, 2015b: Rethinking Indian monsoon rainfall prediction in the context of recent global warming. Nat. Commun., 6, 7154, https://doi.org/10.1038/ncomms8154.

— J. Li, and Q. He, 2017: Variable and robust East Asian monsoon rainfall response to $\mathrm{El}$ Niño over the past 60 years (1957-2016). Adv. Atmos. Sci., 34, 1235-1248, https://doi.org/ 10.1007/s00376-017-7016-3.

Wang, C., and L. Wu, 2012: Tropical cyclone intensity change in the western North Pacific: Downscaling from IPCC AR4 experiments. J. Meteor. Soc. Japan, 90, 223-233, https://doi.org/ 10.2151/jmsj.2012-205.

$\longrightarrow$, and - 2016: Interannual shift of the tropical uppertropospheric trough and its influence on tropical cyclone formation over the western North Pacific. J. Climate, 29, 42034211, https://doi.org/10.1175/JCLI-D-15-0653.1.

$\longrightarrow$, and - 2018a: Future changes of the monsoon trough: Sensitivity to sea surface temperature gradient and implications for tropical cyclone activity. Earth's Future, 6, 919-936, https://doi.org/10.1029/2018EF000858.

$\longrightarrow$, and — 2018b: Projection of North Pacific tropical uppertropospheric trough in CMIP5 models: Implications for changes in tropical cyclone formation locations. J. Climate, $\mathbf{3 1}$, 761-774, https://doi.org/10.1175/JCLI-D-17-0292.1.

— , and B. Wang, 2019: Tropical cyclone predictability shaped by western Pacific subtropical high: Integration of trans-basin sea surface temperature effects. Climate Dyn., 53, 2697-2714, https://doi.org/10.1007/s00382-019-04651-1.

,-- , and L. Wu, 2019a: Abrupt breakdown of the predictability of early season typhoon frequency at the beginning of the twenty-first century. Climate Dyn., 52, 3809-3822, https://doi.org/10.1007/s00382-018-4350-9.

— L. Wu, H. Zhao, J. Cao, and W. Tian, 2019b: Is there a quiescent typhoon season over the western North Pacific following a strong El Niño event? Int. J. Climatol., 39, 61-73, https://doi.org/10.1002/joc.5782.

Wang, G., J. Su, Y. Ding, and D. Chen, 2007: Tropical cyclone genesis over the South China Sea. J. Mar. Syst., 68, 318-326, https://doi.org/10.1016/j.jmarsys.2006.12.002.

Wang, H., and K. Fan, 2007: Relationship between the Antarctic oscillation in the western North Pacific typhoon frequency.
Chin. Sci. Bull., 52, 561-565, https://doi.org/10.1007/s11434007-0040-4.

- J. Sun, and K. Fan, 2007: Relationships between the North Pacific Oscillation and the typhoon/hurricane frequencies. Sci. China, 50D, 1409-1416, https://doi.org/10.1007/s11430-0070097-6.

Wang, X., W. Zhou, C. Li, and D. Wang, 2012: Effects of the East Asian summer monsoon on tropical cyclone genesis over the South China Sea on an interdecadal time scale. $A d v$. Atmos. Sci., 29, 249-262, https://doi.org/10.1007/s00376011-1080-x

Wilks, D. S., 2006: Statistical Methods in the Atmospheric Sciences. Academic Press, 676 pp.

Wu, G., and Coauthors, 2007: The influence of mechanical and thermal forcing by the Tibetan Plateau on Asian climate. J. Hydrometeor., 8, 770-789, https://doi.org/10.1175/ JHM609.1.

Wu, L., C. Wang, and B. Wang, 2015: Westward shift of western North Pacific tropical cyclogenesis. Geophys. Res. Lett., 42 , 1537-1542, https://doi.org/10.1002/2015GL063450.

Xiang, B., B. Wang, W. Yu, and S. Xu, 2013: How can anomalous western North Pacific subtropical high intensify in late summer? Geophys. Res. Lett., 40, 2349-2354, https://doi.org/ 10.1002/grl.50431.

Xie, S.-P., and S. G. H. Philander, 1994: A coupled oceanatmosphere model of relevance to the ITCZ in the eastern Pacific. Tellus, 46A, 340-350, https://doi.org/10.3402/tellusa. v46i4.15484.

—_, K. Hu, J. Hafner, H. Tokinaga, Y. Du, G. Huang, and T. Sampe, 2009: Indian Ocean capacitor effect on Indowestern Pacific climate during the summer following El Niño. J. Climate, 22, 730-747, https://doi.org/10.1175/ 2008JCLI2544.1.

— , Y. Kosaka, Y. Du, K. Hu, J. S. Chowdary, and G. Huang, 2016: Indo-western Pacific ocean capacitor and coherent climate anomalies in post-ENSO summer: A review. $A d v$. Atmos. Sci., 33, 411-432, https://doi.org/10.1007/s00376-0155192-6.

Xuan, S., Q. Zhang, and S. Sun, 2011: Anomalous midsummer rainfall in Yangtze River-Huaihe River valleys and its association with the East Asia westerly jet. Adv. Atmos. Sci., 28 , 387-397, https://doi.org/10.1007/s00376-010-0111-3.

Yan, Z.-B., Z.-H. Lin, and H. Zhang, 2015: The relationship between the East Asian subtropical westerly jet and summer precipitation over East Asia as simulated by the IAP AGCM4.0. Atmos. Oceanic Sci. Lett., 7, 487-492, https:// doi.org/ 10.3878/AOSL20140048.

Yim, S.-Y., B. Wang, and W. Xing, 2014: Prediction of early summer rainfall over South China by a physical-empirical model. Climate Dyn., 43, 1883-1891, https://doi.org/10.1007/s00382013-2014-3.

Zhan, R., and Y. Wang, 2016: CFSv2-based statistical prediction for seasonal accumulated cyclone energy (ACE) over the western North Pacific. J. Climate, 29, 525-541, https://doi.org/ 10.1175/JCLI-D-15-0059.1.

- - - and X. Lei, 2011a: Contributions of ENSO and East Indian Ocean SSTA to the interannual variability of northwest Pacific tropical cyclone frequency. J. Climate, 24, 509-521, https://doi.org/10.1175/2010JCLI3808.1.

, -, and C. C. Wu, 2011b: Impact of SSTA in the East Indian Ocean on the frequency of northwest Pacific tropical cyclones: A regional atmospheric model study. J. Climate, 24, 62276242, https://doi.org/10.1175/JCLI-D-10-05014.1. 
- - , and M. Ying, 2012: Seasonal forecasts of tropical cyclone activity over the western North Pacific: A review. Trop. Cyclone Res. Rev., 1, 307-324, https://doi.org/10.6057/ 2012TCRR03.07.

— - — and M. Wen, 2013: The SST gradient between the southwestern Pacific and the western Pacific warm pool: A new factor controlling the northwestern Pacific tropical cyclone genesis frequency. J. Climate, 26, 2408-2415, https:// doi.org/10.1175/JCLI-D-12-00798.1.

Zhang, Q., L. Wu, and Q. Liu, 2009: Tropical cyclone damages in China 1983-2006. Bull. Amer. Meteor. Soc., 90, 489-496, https://doi.org/10.1175/2008BAMS2631.1.

Zhang, W., G. A. Vecchi, H. Murakami, G. Villarini, and L. Jia, 2016a: The Pacific meridional mode and the occurrence of tropical cyclones in the western North Pacific. J. Climate, 29, 381-398, https://doi.org/10.1175/JCLI-D15-0282.1.

_ , G. Villarini, G. A. Vecchi, H. Murakami, and R. Gudgel, 2016b: Statistical-dynamical seasonal forecast of western North Pacific and East Asia landfalling tropical cyclones using the high-resolution GFDL FLOR coupled model. J. Adv. Model. Earth Syst., 8, 538-565, https://doi.org/10.1002/ 2015 MS000607.

Zhang, X., S. Zhong, Z. Wu, and Y. Li, 2018: Seasonal prediction of the typhoon genesis frequency over the western North Pacific with a Poisson regression model. Climate Dyn., 51, 4585-4600, https://doi.org/10.1007/s00382-017-3654-5.

Zhao, H., 2016: A downscaling technique to simulate changes in western North Pacific tropical cyclone activity between two types of El Niño events. Theor. Appl. Climatol., 123, 487-501, https://doi.org/10.1007/s00704-015-1374-5.

- , and C. Wang, 2016: Interdecadal modulation on the relationship between ENSO and typhoon activity during the late season in the western North Pacific. Climate Dyn., 47, 315-328, https://doi.org/10.1007/s00382-015-2837-1.

, and - 2019: On the relationship between ENSO and tropical cyclones in the western North Pacific during the boreal summer. Climate Dyn., 52, 275-288, https://doi.org/ 10.1007/s00382-018-4136-0.

- L. Wu, and W. Zhou, 2010: Assessing the influence of the ENSO on tropical cyclone prevailing tracks in the western North Pacific. Adv. Atmos. Sci., 27, 1361-1371, https://doi.org/ 10.1007/s00376-010-9161-9.

Zhou, B., and X. Cui, 2008: Hadley circulation signal in the tropical cyclone frequency over the western North Pacific. J. Geophys. Res., 113, D16107, https://doi.org/10.1029/2007JD009156. and - 2011: Sea surface temperature east of Australia: A predictor of tropical cyclone frequency over the western North Pacific? Chin. Sci. Bull., 56, 196-201, https://doi.org/10.1007/ s11434-010-4157-5. 